Policy Research Working Paper 4813

\title{
Month of Birth and Children's Health in India
}

Michael Lokshin

Sergiy Radyakin

The World Bank

Development Research Group

Poverty Team

January 2009 
Policy Research Working Paper 4813

\section{Abstract}

The authors use data from three waves of the India National Family Health Survey to explore the relationship between the month of birth and the health outcomes of young children in India. They find that children born during the monsoon months have lower anthropometric scores compared with children born during the fall and winter months. The authors propose and test four hypotheses that could explain such a

correlation. The results emphasize the importance of seasonal variations in affecting environmental conditions at the time of birth and determining the health outcomes of young children in India. Policy interventions that affect these conditions could effectively impact the health and achievement of these children, in a manner similar to nutrition and micronutrient supplementation programs.

This paper-a product of the Poverty Team, Development Research Group—is part of a larger effort in the department to study the effect of environmental conditions on children's health outcomes. Policy Research Working Papers are also posted on the Web at http://econ.worldbank.org. The author may be contacted at mlokshin@worldbank.org.

The Policy Research Working Paper Series disseminates the findings of work in progress to encourage the exchange of ideas about development issues. An objective of the series is to get the findings out quickly, even if the presentations are less than fully polished. The papers carry the names of the authors and should be cited accordingly. The findings, interpretations, and conclusions expressed in this paper are entirely those of the authors. They do not necessarily represent the views of the International Bank for Reconstruction and Development/World Bank and its affiliated organizations, or those of the Executive Directors of the World Bank or the governments they represent. 


\title{
Month of Birth and Children's Health in India
}

\author{
Michael Lokshin and Sergiy Radyakin* \\ The World Bank
}

Keywords: Nutrition, anthropometry, child health, seasonality, poverty, India

JEL: J12, I32, O12

\begin{abstract}
*Michael Lokshin mlokshin@worldbank.org and Sergiy Radyakin sradyaking@worldbank.org are both at the Development Research Group, World Bank, 1818 H Street NW, Washington D.C., 20433, USA. We thank Harold Alderman, Jishnu Das, Monica Das Gupta, and Toan Q. Do for their constructive comments. The findings, interpretations and conclusions of this paper are those of the authors and should not be attributed to the World Bank, its Executive Directors or the countries they represent.
\end{abstract}




\section{Introduction}

A large literature in economics, human biology and medicine has been devoted to understanding the effects of early childhood conditions on outcomes later in life. Research has consistently shown that the month of birth is an important predictor of health outcomes, morbidity and mortality. But, so far, no convincing theories have been proposed to explain this association.

Most of the studies showing correlation between months of birth and children's health outcomes have been restricted to high-income settings. The correlation between an individual's height and his/her month or season of birth was documented by Weber et al. (1998), for Australia; Kihlbom and Johansson (2004) for Sweden; Shephard et al. (1979) and Koscinski et al. (2004), for Poland. Early exposure to cold conditions was reported to be associated with higher weight during adulthood in England (Phillips and Young, 2000). Van Hanswijck de Jonge et al. (2003), using data from the United States, found that birth weight and early infancy weight gain varied by season and were modified by ethnicity. Tanaka et al. (2007) showed that in Japan the height and weight of schoolchildren were influenced by their months and seasons of birth. We are unaware of any study that directly investigated variations in children's health by season-of-birth in the context of poor developing countries.

In this paper, we use data from three rounds of the India National Family Health Survey (NFHS) to: (i) quantify the effects of the months of birth on children's anthropometrics, and (ii) test four hypotheses explaining the relationship between the months of birth and children's health outcomes. We find that Indian children born during the monsoon months have worse health outcomes than children born during the fallwinter months. The 'month-of-birth' effect is shown to be present in all three waves of the NFHS and persists after controlling for a wide set of observable and unobservable characteristics. The effect is large: the differences in weight and height among children born during the monsoons and other children are comparable to the differences in health outcomes between children born to illiterate mothers and mothers who had completed primary education. 
We formulate and test four hypotheses that might explain the correlation between children's health outcomes and their months of birth. The empirical tests of these hypotheses conclude that the most likely explanation for the observed pattern of changes in children's health by month-of-birth is a higher prevalence of malnutrition and wider exposure to diseases during the lean monsoon season. Our results show that seasonal variations affect the environmental conditions at the time of birth and determine health outcomes for young children in India. Policy interventions that affect such conditions might be as effective in improving children's health as nutrition and micronutrient supplementation programs.

This paper contributes to the research on child health and nutrition in several ways. First, in contrast to the existing medical literature on the effect of the month of birth on individual health, we try to present a comprehensive causal analysis of this phenomenon, taking into account both the socio-economic and environmental factors that might affect children's health outcomes. Second, we analyze the impact of the months of birth on children's health in the context of a poor developing country, as compared to most other literature on this topic which focuses on developed countries. Third, we demonstrate the 'month-of-birth' effect for children younger than three years of age; the majority of studies analyze the consequences of seasonality of birth on outcomes in adult life. Finally, our paper suggests that the omission of the month-of-birth variable in estimators of econometric models on children's nutritional status and health, might lead to significant biases.

The following section describes the setting of our data and shows some descriptive results. Section 3 sets up the main question of the paper. Section 4 outlines and tests the main hypotheses, explaining the association between the months of birth and children's health outcomes. Section 6 offers some conclusions. 


\section{Data and Descriptive Statistics}

This analysis uses data from three waves of the India NFHS (1992/1993, 1998/1999 and $2005 / 2006)^{1}$. NFHS is a survey of representative households, covering states and territories of India containing approximately 99 percent of its population (Kashmir and Sikkim, as well as some remote territories, are not covered). The survey structure corresponds to the typical structure of demographic and health surveys (DHS) conducted in several other countries. Our main sample contains information on 45,279 children from the 1992/1993 India NFHS; 30,984 from 1998/1999; and 48,679 from 2005/2006². These children were residing correspondingly in 33,032; 26,056; and 33,968 households ${ }^{3}$.

The NFHS uses three types of questionnaires: the household questionnaire, the woman's questionnaire and the village questionnaire. The household questionnaire collects information on the family structure and background; caste/tribe of the household head; age, gender, education, employment, and health status of household members; information on public services utilization; and other topics. The woman's questionnaire covers dates and survival status of all births; current pregnancy status; childbearing intentions; and childcare practices_-for women aged 15 to 49. The village questionnaire gathers information on village area and population; diverse infrastructure characteristics such as distance to the nearest town, roads, public transportation (bus); and presence in village or distance to schools and health facilities. Information was also collected on the number of cars, trucks, motorcycles, and TV sets in the villages, as well as whether they have electricity and what the main sources of drinking water are.

Because the NFHS registers no information on household income or consumption, we use a constructed household wealth. The wealth index is the first principal component of a number of household assets - such as clocks, radios, TVs, VCRs, refrigerators, bicycles, motorbikes, cars, as well as the types of utilities used by

\footnotetext{
${ }^{1}$ Detailed information on NFHS methodology and sample design is made available by the International Institute of Population Sciences (IIPS) at: http://www.nfhsindia.org/. The data is available from MEASURE DHS, Macro International Inc.: http://www.measuredhs.com.

2 The number of observations in the 1998/1999 round is smaller because NFHS-2 collected height and weight information for only the last two children, under three years of age, of ever-married woman interviewed.

${ }^{3}$ In 1992/1993, measurements of height were not collected in Andhra Pradesh (AP), Himachal Pradesh (HP), Madhya Pradesh (MP), Tamil Nadu (TN), and West Bengal (WB).
} 
the households (for example, Filmer and Pritchett 2001; Rutstein and Johnson 2004). The descriptive statistics for the main variables used in this paper are shown in Table 1.

The NFHS data provide measurements of height and weight for children under 48 months of age in 1992/1993, under 36 months in 1998/1999 and under 60 months in 2005/2006. For comparability between the different NFHS rounds, we restrict our sample to children less than 36 months of age. We focus on the age-adjusted measures of heightfor-age (HAZ) and weight-for-age (WAZ), which reflect the children's development relative to a reference population of well-nourished children ${ }^{4}$ (WHO 2006). These measures reflect different dimensions of the children's development: height-for-age (stunting) reflects the long-term effects of malnutrition, while weight-for-age (underweight) reflects both long- and short-term dietary effects (WHO 1995).

Malnutrition is highly prevalent in India. About 80 percent of children under the age of 3 were mildly, moderately, or severely underweight in 1992, with minimal changes in 1998 and $2005^{5}$. In 1992, 72 percent of boys and 70 percent of girls were stunted. The proportion of stunted children had decreased to 65 percent by 2005 . According to NFHS data, the overall averages of HAZ and WAZ rose over the years for both boys and girls. Figure 1 demonstrates that the average HAZ had risen for boys from -1.9 in 1992 to -1.5 in 2005; WAZ grew from -2.0 in 1992 to -1.8 in 2005. Girls experienced similar improvements in health outcomes between 1992 and 2005.

The distribution of births by calendar months for the three rounds of NFHS is presented in Figure $2^{6}$. The proportions of boys and girls born in each month are similar. The highest birth rates are registered in August, September and October--these children

\footnotetext{
${ }^{4}$ A report by Nutrition Foundation of India concluded that the WHO standard was generally applicable to Indian children (IIPS 2000, page 265). The nutritional status of children calculated according to these measures is compared with the nutritional status of a reference population recommended by the WHO (Dibley et al. 1987). The use of this reference group is based on the empirical findings that well-nourished children in all populations for which data exist follow similar growth patterns (Martorell and Habicht, 1986). Across the NFHS rounds, about 10 percent of eligible children were not measured, either because the children were not at home or because their mothers refused to allow the measurements (Lokshin Das Gupta and Ivaschenko, 2005).

${ }^{\mathbf{5}} \mathrm{A}$ child is considered to be mildly underweight if its WAZ is from -1 to -2 standard deviations (SD) from the mean. Children with WAZ from -2 to -3 SD are considered to be moderately underweight, and children with WAZ less than -3 are considered severely underweight. Similar ranges are applied for stunting categories of HAZ.

${ }^{6}$ The results shown in Figure 2 are calculated based on the sample of children younger than 36 months of age born in every household. This sample includes children who did not survive. The distribution of birth by month, constructed based on the sample of survived children, is similar to the one shown in Figure 2.
} 
were conceived in winter. The least number of children were born during the winter months of December, January and February--these children were conceived in spring. The wedding season in India, which falls in the months from November to February, could partially explain this seasonality of birth (Medora 2003).

Figure 3 shows the proportion of children, among all the children born in a particular month, who died before the age of 3 years. Child mortality declined from 1992 to 2005. In 1992, 14.8 percent of boys and 15.2 percent of girls died before reaching the age of 3 years. By 2005, these figures had declined to 11.5 and 11.8 percent respectively. The highest mortality rates, among children of both genders, were registered in the spring-summer months of April, May, June, and July. Data for boys from 1992 showed that child mortality declined during the winter months and the difference in mortality rates between summer and winter was 2 percentage points.

\section{Setting up the Problem}

Figure 4 shows the changes in Z-scores by month of birth for boys and girls in the three rounds of $\mathrm{NFHS}^{7}$. Health outcome measures appear to be lowest for children born in summer and improving for children born in fall and early winter. This relationship holds for both girls and boys and for WAZ and HAZ measures. For example, if the average HAZ for boys born in June of 1992 was about -2.27 (standard error of 0.05), HAZ for boys born in December of the same year was -1.73 (SE 0.06). The average HAZ increased from -2.33 (SE 0.05) for girls born in June to -1.69 (SE 0.05) for girls born in December. The differences in health outcomes between summer and fall/early winter months persist in 1992 and 1998 and exhibit a decline in 2005.

Would the effect of the birth month on a child's health be significant after controlling for the characteristics of a household, a mother, and a child? To find the answer to this question we rely on a standard theoretical framework of household utility maximization that incorporates the production function determining child's health (Behrman and Deolalikar, 1988). According to that theory, a household utility is a

\footnotetext{
${ }^{7}$ A relatively large gap between the anthropometric measures of children born in December and January persists for both WAZ and HAZ in all rounds of NFHS. We were not able to find an explanation for the phenomenon.
} 
function of consumption and leisure of household members, as well as the quality and quantity of their children. A household maximizes its utility subject to standard budget constraints and the restrictions imposed by the health production function. The household demand for child health (child's height and weight) depends on a set of exogenous characteristics of a child $X_{i}$, household characteristics $X_{h}$, characteristics of its mother $X_{m}$, community characteristics $X_{c}$, and some unobserved factors captured by random error $\varepsilon_{i}$ (Thomas, Strauss and Henriques, 1991). This relation can be expressed as:

$$
Z_{i}^{s}=Z_{i}\left(X_{i}, X_{m}, X_{h}, X_{c}, \varepsilon_{i}^{s}\right), s=W A Z, H A Z .
$$

The child's characteristics include age, sex, birth order, and month of birth. The mother's characteristics include her age, educational attainment and employment status. Characteristics of a household include household size, socio-demographic composition, household wealth index, religion, and caste. Community characteristics include availability of community services and infrastructure. In the linearized form, the production function of child's health (1) can be expressed as:

$$
Z_{i}^{s}=\sum_{k=1}^{11} \alpha_{k}^{s} M_{i k}+\pi^{s} \bar{X}_{i}+\varepsilon_{i}^{s} \quad s=W A Z, H A Z,
$$

where $M_{i k}$ is a dummy variable equal to 1 if child $i$ is born in month $k$, vector $\bar{X}_{i}$ combines the child's, mother's, household's and community's characteristics, and $\alpha_{k}^{s}$ and $\pi^{s}$ are parameters. Table 2a shows the coefficients of the linear regressions for WAZ and HAZ for children younger than 36 months, and for three rounds of NFHS. The 'month-ofbirth' effect persists when we control for a wide set of exogenous characteristics in (2). Relative to December, children born in other months have worse health outcomes, with the largest negative differences showing up in May, June and July. In Table 2b, we add three variables on the access to health facilities: distances from the village to a hospital, a primary health center and a health sub-center. Table 2b shows the estimates for 1992 and 1998 , as the information on these distances was collected only for rural population in the first and second rounds of the NFHS. We still find a strong month-of-birth effect under this extended specification.

The coefficients on the control variables in the regressions used in Tables 2a and $2 \mathrm{~b}$ reveal the expected relationship between child health outcomes and the characteristics 
of a household, a mother and a child. A higher birth order has a negative impact on the health outcomes of both boys and girls (for example, Horton 1988). Consistent with the findings in the literature (for example, Holmes 2006), health outcomes deteriorate with the age of a child. Children living in wealthier households and with better-educated mothers have higher WAZ and HAZ. The relationship between a child's health and his/her mother's age has an inverted U-shape: the outcomes improve with the mother's age till the age of about 40 , and then decline for children of older mothers.

The potential endogeneity of the month-of-birth could have strong implications for the findings of this paper. Suppose it is known to parents that children born during certain months of the year are more likely to get sick. Then parents would try to plan their pregnancies to give birth in months most favorable for their children's health. In the presence of an unobserved heterogeneity in the parental inputs to the production function of a child's health, the observed variation in child health outcomes by month-of-birth could be partially attributed to differences in the parental behavior (for example, Rosenzweig and Shultz 1982). In that case, the estimates that fail to control for such heterogeneity would provide an upper bound for the effect of the month of birth on child's health.

Assume the error terms in (2) can be decomposed into the child-specific IID error term $\mu_{i j}^{s}$, and the household-specific unobserved factor $v_{j}^{s}$, capturing the heterogeneity in parental inputs to the production function of children's health. $v_{j}^{s}$ can be correlated with the month a child is born in. Then, equation (2) will have a following form:

$$
\begin{aligned}
Z_{i j}^{s}=\sum_{k=1}^{11} \alpha_{k}^{s} M_{i j k}+\pi^{s} \bar{X}_{i j}+\left(\mu_{i j}^{s}+v_{j}^{s}\right) s=W A Z, H A Z \\
\text { s.t. } \operatorname{Corr}\left(M_{i j k}, \mu_{i j}^{s}\right)=0 ; \operatorname{Corr}\left(M_{i j k}, v_{j}^{s}\right) \neq 0 .
\end{aligned}
$$

Under the assumption that the unobserved heterogeneity in parental inputs is constant over time (siblings), we can account for the endogeneity of the month-of-birth by estimating the fixed-effect regression (FE) on the sample of siblings, thus removing the household-specific parental component $v_{j}^{s}$. This regression includes explanatory variables that differ among the siblings living in the same household: dummies for the month of birth, age of a child and the child's birth order. Table 2c shows the FE 
coefficients on the 11 dummies for the months of birth, most of which are significant ${ }^{8}$. The seasonal patterns in child health are similar to patterns revealed by OLS estimations: children born in fall-winter months are healthier compared to children born in summer. The month-of-birth coefficients from the FE model are larger than the coefficients estimated by OLS. The difference can be explained by the fact that the FE regression is estimated on a relatively small sample of households—each with two children below age 3 , while the sample for OLS regression includes all households ${ }^{9}$.

The average WAZ and HAZ of children born during the monsoon season is about 0.5 standard deviations (SD) lower than the average WAZ and HAZ of children born in the fall-winter months (Figure 4). After controlling for the characteristics of the child, the mother and the household they live in, the 'month-of-birth' effects ranged from 0.2 to 0.4 SD for both measures (Table 2). The magnitude of this effect is similar to the differences in Z-scores between children of illiterate mothers and mothers with incomplete secondary education, as observed in our data. Alderman, Hoogeveen and Rossi (2005) report that the anthropometric measures of children born during the ‘lean’ season in Tanzania are 0.2 to $0.4 \mathrm{SD}$ lower than the measures of children born in other months of the year. These effects are comparable with the effects of nutrition programs and the estimated elasticities of the changes in households' and mothers' characteristics. For example, in Bangladesh, the average WAZ and HAZ of children with illiterate mothers is about 0.4 SD lower than the WAZ and HAZ of children whose mothers hold university degrees (Moestue and Huttly, 2008). Similar effects of maternal education on children's anthropometrics are found by Alderman and Garcia (1994) for Pakistan, and Kassouf and Senauer (1996) for Brazil. The provision of micronutrient supplements resulted in a 0.2 SD increase in HAZ and 0.1 SD in WAZ for children in Vietnam and Mexico (Thu et al., 1999; Rivera et al., 2001). Vaccinations against upper respiratory illness improve WAZ by about 0.5 SD and HAZ by more than 1 SD, according to Alderman and Garcia (1994).

\footnotetext{
${ }^{8}$ The F-tests on the FE, in all regressions in Table 2c, reject the pooled-OLS specification in favor of the FE specification.

${ }^{9}$ Several studies point to problems with the quality of age data in NFHS (for example, Bhat 1995;

Narasimhan et al., 1997; Mishra, Lahiri and Luther 1999). This measurement error in reported age would attenuate our results towards zero, so that the estimated effect of the months of birth on children's health would be the lower bound (in absolute terms) of the true effects.
} 
The above estimations demonstrate the consistently strong correlation between the months-of-birth and children's health outcomes for boys and girls, across different regression specifications, years and for different samples. In the next section, we try to establish the causality of this correlation.

\section{Explaining the Correlation between the Month of Birth and Health Outcomes}

Several theories are proposed in literature to explain the variation in children's health outcomes by season of birth. These theories attribute variations in outcomes by month-ofbirth to seasonal differences in prenatal and postnatal nutrition and the disease environment; social differences in the seasonal distribution of births; the selective survival at birth and during infancy; and planned versus unplanned pregnancies. We discuss each of these theories in turn.

The 'nutrition-disease' hypothesis

We start our analysis by testing the 'nutrition-disease' hypothesis. This hypothesis is based on a body of evidence about the importance of prenatal and postnatal nutrition and the disease environment for children's health outcomes (Doblhammer 2004; Doblhammer and Vaupel 2001). Both diet and the absence of disease are crucial for the adequate growth of children and may work in synergy (Alderman and Garcia, 1994). Changes in food supply and food quality affect intrauterine growth. In India, mothers who gave birth in the fall or early winter season had access to better quality food and fresh fruits and vegetables during most of their pregnancies. Occurrences of infectious diseases that impact the mother, fetus and new born child are correlated with seasonal climatic changes because of the interaction between climate and the vectors of disease, and the interaction between the nutritional status and immune functions of a mother and her child. Other seasonal factors that might affect the health of children include the effect of exposure to sunlight on the children's and mothers' metabolisms, and the seasonal variations in availability and rates of vitamin absorption.

The monsoon is a climatic event that separates seasons and is essential for agriculture in India. The deprivation of nutrients and other health-related intakes during 
the monsoon was shown to have a considerable effect on the health status of women and children in India (for example, Chambers 1982; Sahn 1987). The monsoon is associated with heavy rains that bring a multitude of diseases. Drinking water gets contaminated and results in a high incidence of water-borne gastro-intestinal infections (Khatiwada and Rimal, 2007) and cholera (Saraswathi and Deodhar, 1990). Excess humidity aggravates skin conditions, asthma and eclampsia (Subramaniam, 2007). Mosquito- and rat-borne diseases such as dengue (Bharaj et al. 2008) and malaria (Kabanywanyi, et al. 2008) are transmitted faster in the wet and humid environment created by the monsoon.

The NFHS provides no data on the nutritional intake of mothers during pregnancy and of children during the first months of their lives. Also, the survey does not collect histories of illnesses during these periods. In the absence of these data, we use household wealth and the education of the mother as proxies for the nutritional status and disease environments into which the children were born. We argue that wealthier households have better means to smooth-out consumption of their children during the lean season and can obtain better health care if their children become sick. Maternal education has a strong positive impact on children's nutrition and health outcomes via modern attitudes towards health care and reproductive behavior (Caldwell 1979; Thomas Strauss and Henriques 1991; Glewwe 1999).

To test the 'nutrition-disease' hypothesis, we regress WAZ and HAZ on a set of explanatory variables that include the socio-demographic characteristics of a household, a household wealth index, characteristics of the mother (including her educational attainments), location dummies, month-of-birth dummies, and interactions of the monthof-birth with wealth index $I_{i}$ and years of mother's education $E_{i}$. This regression can be expressed as:

$$
Z_{i}^{s}=\sum_{k=1}^{11} M_{i k}\left[\alpha_{k}^{s}+\beta_{k}^{s} I_{i}+\gamma_{k}^{s} E_{i}\right]+\pi^{s} \bar{X}_{i}+\varepsilon_{i}^{s} \quad s=W A Z, H A Z
$$

A significance of coefficients on month-wealth interactions $\left(\boldsymbol{\beta}_{\boldsymbol{k}}^{s}\right)$ or month-education interactions $\left(\gamma_{k}^{s}\right)$ would point to the presence of seasonal differences in the effect of wealth and maternal education (as a proxy for nutrition and health care) on children's health outcomes. 
Table 3 shows the results of the F-test ( $\chi^{2}$ test for the FE model) on the joint significance of coefficients on the interactions of household wealth and maternal education with the month of birth (separately for boys and girls and for three waves of $\mathrm{NFHS}^{10}$ ). The table is based on three econometric specifications: Specification 1 uses the standard controls to estimate (4); Specification 2 expands this set of variables by adding community-level indicators on access to health care facilities (thus restricting our sample to rural households and to the 1992 and 1998 waves of NFHS); Specification 3 is a fixed effect regression estimated on the sample of siblings. In Specification 3 we tried to address the potential endogeneity of the month of birth (discussed in the previous section) and use the FE regression to control for time-invariant unobservable characteristics that might be correlated with the month of birth. Because of a strong correlation between maternal education and household wealth, we show three tests for each specification/year/gender combination. The first group of tests is based on regressions where we include the interaction between wealth and month-of-birth only (to test the significance of $\beta_{k}^{s}$ ). The second group is based on the regressions with interactions of years of maternal education and the month of birth (to test the significance of $\gamma_{k}^{s}$ ). The last group of tests includes both interactions and tests the joint significance of $\beta_{k}^{s}$ and $\gamma_{k}^{s}$.

These estimations demonstrate that household wealth and the education of mothers have significant effects on children's health outcomes by month-of-birth. The seasonal variations in WAZ and HAZ for children living in wealthier households and with better educated mothers were smaller compared to the health outcomes of other children $\left(\beta_{k}^{s}>0\right.$ and $\left.\gamma_{k}^{s}>0\right)$. For HAZ, the F- and $\chi^{2}$-tests strongly reject the nullhypotheses of no heterogeneity by maternal education and household wealth for both genders. The results of tests based on Specification 2 are mixed but the majority of tests point to the joint significance of the interaction terms of household wealth and maternal education with child's month of birth. For WAZ, the situation is less clear. The F-tests fail to reject the null-hypothesis of no heterogeneity in about two-thirds of the cases ${ }^{11}$.

\footnotetext{
${ }^{\mathbf{1 0}}$ The complete regression is available from authors.

${ }^{11}$ We tried to differentiate between the impact of prenatal and postnatal environments on the variations in children's health outcomes. We regress the mothers' subjective assessments of their children's weights at birth (discussed later in this section) on the month-of-birth dummies and the standard set of controls. The
} 
The 'socio-economic' hypothesis

If, during certain seasons, more children are born in better-educated and/or wealthier families, the correlation between children's health outcomes and their monthsof-birth can be attributed to the difference in resources available to the children (for example, Bronson 1995). In industrialized countries, the seasonality of birth can be explained by cultural patterns. In the less-developed countries, women's involvement in agricultural activities, food availability, the seasonality of marriages, and male migration are more important determinants of the seasonality of birth. Seasonal patterns of birth in Austria, Denmark and Australia are documented by Knodel and Wilson (1981). Lam and Miron (1991, 1996) find that summer temperature extremes reduce the number of conceptions in southern US. Seasonal variations in birth rates are associated with the socio-demographic characteristics of mothers in the Czech Republic (Bobak and Gjonca 2001). Panter-Brick (1996) demonstrates that, in Nepal, seasonal rates of pregnancies are determined, among other things, by seasonality of marriage (which, in turn, is determined by agricultural cycles) and marital disruptions related to out-migration of males and agricultural activities; the peaks of conception are observed in the beginning of the monsoon season of June-July and rice harvesting in December. Rajagopalan, Kymal and Pei (1981) documented the strong effect of agricultural cycles on births in Tamil Nadu in India, emphasizing large differences in the seasonality of birth between urban and rural areas.

To test the 'socio-economic' hypothesis, we estimate the relationships between the month of birth with household wealth and maternal education, controlling for the characteristics of a household and a mother. This relationship can be expressed as:

$$
\operatorname{Prob}\left(M_{i k}=1\right)=f\left(\boldsymbol{\beta}_{\boldsymbol{k}} I_{i}+\gamma_{\boldsymbol{k}} E_{i}+\pi_{k} \bar{X}_{i}+\varepsilon_{i k}\right), k=1, \ldots, 12,
$$

where $\operatorname{Prob}\left(M_{i k}=1\right)$ is the probability of child $i$ to be born in month $k$. Given an unordered structure of the month-of-birth variable and assuming that $\varepsilon_{i k}$ 's are independent and identically Gumbel distributed, we applied the multinomial logit specification for this

correlation of weight at birth with the month of birth would indicate that the observed seasonal variations in children's health can be explained by the variations in prenatal conditions. The coefficients on month-ofbirth dummies in this regression are insignificant, providing us with no evidence for differentiating between the impacts of prenatal and postnatal conditions. 
estimation ${ }^{12}$. A significance of the coefficients $\boldsymbol{\beta}_{\boldsymbol{k}}$ and $\boldsymbol{\gamma}_{\boldsymbol{k}}$ would indicate that household wealth and education of the mother affect the probability of a child to be born in a certain month of the year, thus supporting the 'socio-economic' hypothesis.

Table 4 shows the estimated coefficients on the wealth index for 11 month-ofbirth categories for boys and girls and for three waves of NFHS. In 1992, the coefficients on the wealth index and maternal education are significant only for boys born in October; for girls, household wealth and education of the mother have no significant effect on the probability of being born in a particular month. For boys in the 1998 sample, the effects of wealth and mothers' education on the month of birth are significant. But the pattern of this significance differs from the patterns we would expect to observe based on Figure 4 . For example, in the 1998 sample, better-off households are more likely to have their children born in the months of February, May, August, October, and November. But May and August are the 'bad' months to be born in, in terms of health outcomes. We find no effect of wealth and maternal education on girls in the 1998 sample and for children surveyed in 2005. The results of likelihood ratio tests of the significance of household wealth index and maternal education in determining a child's month of birth are shown in the bottom part of Table 4. These tests confirm that both wealth index and maternal education contribute little to determining the month of year in which a child will be born.

Thus, we can conclude that our empirical results provide no support of the "socioeconomic hypothesis".

\section{The 'selective survival' hypothesis}

The third hypothesis explains the seasonal differences in children's health outcomes by 'selective survival' of strong children at birth and during infancy. The hypothesis postulates that if mortality at birth is higher in a certain season than mortality in other seasons, children that survive during the high-mortality season might be more robust and would have better outcomes later in life (Samuelson and Ludvigsson, 2001). In other words, weak children born in high mortality seasons die and only the strong

\footnotetext{
12 The Independence of Irrelevant Alternatives (IIA) assumption of the Multinomial Logit is clearly violated in the case of modeling the month of birth. A multinomial probit model (MNP) would be more appropriate for estimating (5). However, estimation of MNP with 12 categories appears to be computationally infeasible.
} 
children survive. Alternatively, children are switched from breastfeeding to supplementary milk and solid food at about six months after birth--this switch might be associated with higher child mortality (Barrera 1990; Olango and Aboud 1990), with higher chances of survival for stronger children. Doblhammer and Vaupel (2001) show that in Denmark, the death rate for infants born in June is 32 percent higher than the death rate of those born in January. Similar seasonal patterns are found by Breschi and Bacci (1998) for Switzerland and Belgium. In Gambia and Bangladesh, birth during the hungry season resulted in excess mortality during the first year of life (Moore et al., 2004).

The NFHS asks mothers to categorize the weight of their children at birth as large, average or small ${ }^{13}$. We use this subjective assessment as a proxy for health endowments at birth. The weight of a child at birth influences his/her health and prospects for survival (for example, Rosenzweig and Shultz 1982). The distribution of the answers to this question for three waves of NFHS is shown in Table 5. The weight of about 20 to 25 percent of children was smaller than average according to their mothers' assessments.

Let $S_{i}^{*}$ be a latent variable determining the survival of a child, which is a function of its health endowments at birth (weight $W_{i}$ ), as well as maternal and household characteristics. Let $S_{i}$ be an observed event of child $i$ surviving longer than 12 months. Then:

$$
\begin{aligned}
& S_{i}^{*}=\sum_{k=1}^{11} M_{i k}\left[\alpha+\gamma_{k} W_{i}\right]+\beta W_{i}+\pi X_{i}+\varepsilon_{i} \\
& S_{i}=1 \text { if } S_{i}^{*}>0 ; S_{i}=0 \text { if } S_{i}^{*} \leq 0
\end{aligned}
$$

To test whether selective child mortality during the first months after birth explains the variation in health outcomes, we estimate the probability of a child surviving past age 3 as a function of the characteristics of a household, a mother, and a child; month-of-birth dummies; and the interaction between the month-of-birth and weight at birth. Under the assumption that $\varepsilon_{i}$ is distributed normally, the probability of survival $(S=1)$ can be estimated by the binary probit model. The significance of the coefficients on the

\footnotetext{
${ }^{13}$ The direct measurement of children's weight at birth is available in NFHS only for a small sub-sample of children. The weight at birth was reported for 2.9 percent of children in the 1992 sample, 3.2 percent in the 1998 sample, and 8.1 percent in the 2005 sample.
} 
interactions between the month of birth and the assessed birth weight ( $\gamma_{k}$ 's) in (6) , rejects the null hypothesis that the survival probabilities of weak and robust children, born in a certain month of the year are the same.

The probit estimations of (6) show that children of a higher birth order, born in poorer households or with younger mothers, and children born small (weak) are more likely to die in the first year after birth ${ }^{14}$. The sample for this estimation includes all children born in the family. Table 6 shows that while children born in certain months of the year, whose weight at birth was assessed as small, were less likely to live past the age of 12 months, the pattern of survival is inconsistent with the observed monthly variations in children's health outcomes. For example, in the 1992 sample, boys that were weak at birth were less likely to survive if they were born in April, May, July, and October. According to the 'selective survival' hypothesis, this would result in observations of better health outcomes for children born during these months, which is not the case. The probability to survive for weak children appears to be unaffected by their month of birth for the sample of girls in 1992 and the boys sample from 1998.

Based on this evidence, our results do not support the 'selective survival' hypothesis.

\section{The 'unplanned pregnancy' hypothesis}

Assume that parents believe that certain months are 'bad' for their children to be born in. Then, in order to improve their children's health outcomes, parents would plan their pregnancies to give birth during the 'good' months. Under this assumption, children born during 'bad' months would more likely be a result of unplanned pregnancies and thus have disadvantaged health status (Kost et al., 1998) ${ }^{15}$. If this hypothesis is true, the observed variation in children's anthropometrics across the months of the year could be explained by the higher proportion of unplanned births during the monsoon season. The

\footnotetext{
${ }^{14}$ To make the categories of the weight-at-birth question consistent across waves of the NFHS surveys, we collapsed into one category the two lowest categories in the 1998 sample, and the two highest and two lowest categories in the 2005 sample.

${ }^{15}$ A paper by Do and Phung (2008) shows that the difference in outcomes between children born in the 'good' and 'bad' years according to the Chinese horoscope can be explained by the fact that children born in 'bad' years are more likely to be unwanted, that is, to be the result of unplanned pregnancies.
} 
NFHS questionnaire asked mothers whether their pregnancy with a particular child was desirable or not--in the form of the following question:

In the time you became pregnant with (Name) did you want 1) to become pregnant then 2) to wait until later 3) no more children at all?

The distribution of the answers to this question (for three years of the survey) is shown in Table 7. Across the different rounds of the survey, the birth of about 20 percent of children could be considered unplanned--that is, the mothers of these children either wanted to have children later or did not want to have more children at all. There are no significant differences in the shares of desirable pregnancies of boys and girls because parents cannot select the sex of the child at the time of conception ${ }^{16}$.

We use these data to test the 'unplanned pregnancy' hypothesis empirically. We estimate the probability of a child being born in a certain month of the year as a function of the 'desirability' of a child and a wide set of controls.

$$
\operatorname{Prob}\left(M_{i k}=1\right)=f\left(\boldsymbol{\eta}_{\boldsymbol{k}} D_{i}+\pi_{k} \bar{X}_{i}+\varepsilon_{i k}\right), k=1, \ldots, 12,
$$

where $D_{i}$ is the 'child desirability' dummy, that is equal to one if a mother wanted to have that child when she became pregnant, and zero otherwise. A significance of coefficients on the 'child desirability' dummies ( $\boldsymbol{\eta}_{\boldsymbol{k}}$ 's) would indicate the concentration of unwanted pregnancies in some months of the year. Table 8 shows that for the 1992 and 1998 samples, 'child desirability' had virtually no effect on the probability of children being born in a certain month of the year. In 2005, boys who were wanted by their parents were more likely to be born in May, June and September. For girls in the 2005 sample, the 'desirability of birth' increased their likelihood of being born during the summer months and in January, February, April, and November. These patterns of births would result in a variation in health outcomes, very different from those observed.

A mother's opinion about the 'desirability' of her child at the time of conception could be subject to recall errors. Such measurement errors would attenuate the coefficients of interest. To address this issue, we instrument the 'desirability of birth' variable with the gender composition of older siblings in the household. Our exclusion restriction is based on the argument that the genders of the siblings would affect the

\footnotetext{
16 Though the observed ratio of desired boys and girls could be influenced by selective abortion after conception.
} 
'desirability' of a child for its parents (for example, Thomas 1994; Duflo 2003) and would have no direct effect on the month the child is born in. In this two-stage procedure, we first estimate a binary probit of 'desirability of birth' of a particular child, as a function of the characteristics of its mother, household characteristics and the gender composition of the child's siblings ${ }^{17}$. In the second stage, we estimate the multinomial logit of the month of birth on a set of maternal and household characteristics and the predicted, at the first stage, indicator of desirability. The bottom panel of Table 8 shows the coefficients on the instrumented 'desirability of birth' variable in the multinomial logit estimation ${ }^{18}$. Similar to the first specification, the instrumented 'desirability' variable has no impact on the probability of being born in a particular month. Thus, neither of the estimations supports the 'unplanned pregnancy' hypothesis.

\section{Sensitivity analysis}

We test the stability of our results using alternative econometric specifications and different samples. First, we replicate all the results presented above using the months of birth relative to the beginning of the monsoon season. The reason for this is that the monsoon season starts in late May/early June in the southern states of India and in late July in North India. Figure 5 shows the average WAZ and HAZ by months-of-birth, normalized to the beginning of the monsoon season. For example, children born in June in the southern states of India would have a normalized month-of-birth of 0 , and children born in November would have a normalized month-of-birth equal to 6 . The trends in health outcomes depicted in Figure 5 are similar to those of Figure 4: WAZ and HAZ of children born during the monsoon months are usually lower than the health outcomes of children born during the six months after the start of the monsoon. The 'month-of-birth' (relative to the beginning of monsoon) effect persists after controlling for observable and

\footnotetext{
${ }^{17}$ We use 'household already has a male child' and 'the previous child was a boy' as instruments for 'desirability' of children.

${ }^{18}$ The $\chi^{2}$-tests of the significance of our instruments are shown in the last row of Table 8. Our instrument (the gender composition of the older siblings) is significant at $\mathrm{p}<0.01$ in the first stage probit estimation for boys in all rounds of the survey, and for girls in 2005. We address the concern about the robustness of our results in the presence of weak instruments by estimating the first stage equation by the linear probability model. In the estimations on the sample of boys in all rounds and on the sample of girls in 2005, the Fstatistics on our excluded instruments are larger than the 'rule-of-thumb' critical value for the Stock-Yogo test $(\mathrm{F}$-stat $=10)$ for weak instruments (Stock and Yogo, 2002). The standard errors for these instrumented estimates are obtained by bootstrapping.
} 
unobservable characteristics of a child and his/her family. As in the case of calendar month-of-birth, the 'nutrition-disease' hypothesis seems to be most plausible in explaining the variation in health outcomes by month-of-birth relative to the beginning of the monsoon.

We also assess how our results would change if we use trimesters, quarters and semesters of birth instead of the month of birth. In addition to calendar seasons, we define three subtropical seasons, and the hungry and harvest seasons, relative to the start of the monsoon in a particular area (as in Moore et al., 2004). The three subtropical seasons are: the monsoon season (June/July-September/October), the cool-dry winter season (October/November-February/March) and the hot-dry season (March/AprilMay/June). The hungry season starts in June/July and ends in December/January. Our main results hold when we use these different timeframes. Expectedly, the larger the time span, the weaker the impact of the season on health outcomes--in other words, we find that trimestral variations in WAZ and HAZ are larger compared to quarterly and halfyear variations.

Another serious concern about the stability of our results is the impact of the sharp deterioration in health outcomes of children after they are switched from breast milk to solid food (in India this happens 4 to 6 months after birth) (for example, Barrera 1990; Olango and Aboud 1990). To address this concern, we repeat our analysis and test our hypotheses on a sample of children older than 12 months. Again, our main conclusions remain the same: the environmental conditions around the date of birth of a child in India play an important role in determining his/her health outcomes later in life.

\section{Conclusions}

In this paper, we use data from three waves of the India NFHS to explore the relationship between the month-of-birth and health outcomes of young children in India. We demonstrate that children's anthropometric scores (WAZ and HAZ) vary significantly with the month of birth: children born during the monsoon months have consistently worse health outcomes compared with children born in the fall-winter season. The 'month-of-birth' effect persists after controlling for a wide set of observable and 
unobservable characteristics of the child, the mother and the household in which they live. The size of this effect ranges from 0.1 to $0.5 \mathrm{SD}$ of the WAZ and HAZ, and is comparable to the effects of maternal education and nutritional supplementation programs on children's health as found in other countries.

We propose four hypotheses to explain the month-of-birth variation in children's health: (i) the 'nutrition-disease' hypothesis related this variation to the higher prevalence of diseases and malnutrition during the monsoon season; (ii) the 'socio-economic' hypothesis assumed different seasonality of birth for different socio-economic groups; (iii) the heterogeneity in the health composition of survived children is the basis for the 'elective survival' hypothesis; and (iv) the 'unplanned pregnancy' hypothesis explains seasonal differences in children's health by the differences in health outcomes for planned and unplanned children.

We test these hypotheses empirically, controlling for a wide range of observable characteristics and using the fixed effect and instrumental variable approaches to account for the effects of unobservable factors. Based on the results of these tests, we conclude that the most likely explanation for the observed patterns of the changes in children's health by the month of their birth is the higher prevalence of malnutrition and wider exposure to diseases in the lean season of the monsoon.

Improving children's health is an important development objective of many international organizations (World Bank 2002). Our results demonstrate the significance of seasonal changes of environmental conditions in determination of children's health. Interventions to improve these conditions could have a positive impact on the health and achievements of children. Current policies aimed at enhancing children's nutritional status and health fail to incorporate measures that differentiate between children born in different months of the year (Elder, Kiess and de Beyer, 1996). It appears that low-cost modifications to existing nutritional programs, which take into account the season of birth, may have a large impact on the health of Indian children. For instance, changes in the immunization schedule could help offset the negative impact of diseases during the monsoon season. Information campaigns could emphasize the seasonal differences in maternal and child care practices. Supplementary feeding and infectious disease control 
programs should be designed to address different needs of mothers and children born in different seasons.

While pointing out the importance of seasonal factors in explaining the variations in children's health, our paper provides no information on the channels through which these factors affect children's health. Possible next steps in this research could involve studies to differentiate between the seasonal impacts of prenatal and postnatal conditions; understand the behavioral responses of households to offset the negative environmental conditions for children born during the 'bad' season; and analyze the channels through which the environment, at the time of birth, affects individual health. Finding answers to these questions would help in the design of more effective programs to improve the health and achievement of Indian children over their lifetimes. 


\section{References}

Alderman, H. and M. Garcia (1994) "Food Security and Health Security: Explaining the Levels of Nutritional Status in Pakistan,” Economic Development and Cultural Change, Vol. 42(3): 485-507.

Alderman, H., Hoogeveen, H. and M. Rossi (2005) "Reducing child malnutrition in Tanzania: Combined effects of income growth and program interventions”, Economics and Human Biology, Vol. 4(1): 1-23.

Barrera, A. (1990) "The role of maternal schooling and its interaction with public health programs in child health production.” Journal of Development Economics, Vol. 32: 69-91.

Berman, J. and A. Deolalikar (1988) "Health and Nutrition.” In Handbook of Development Economics, Vol. 1, ed. Chenery, H. and T. Srinivasan. Amstardam, North Holland: 631-704

Bharaj, P., Chahar, H., Pandey, A., Diddi, K., Dar, L., Guleria, R., Kabra, S. and S. Broor, (2008) "Concurrent infections by all four dengue virus serotypes during an outbreak of dengue in 2006 in Delhi, India.” Virology Journal, Vol. 5(1)

Bhat, P., (1995) "On the quality of birth history data collected in National Family Health Survey, 1992-93.” Demography India, Vol. 24(2): 245-58

Breschi, M. and M. Bacci, (1998) "Month of birth as a factor in children's survival." in Desjardins, B. and P. Brignoli ed. Infant and child mortality in the past, Oxford, Clarendon press: 157-173.

Bronson, H., (1995) "Seasonal variation in human reproduction: environmental factors." The Quarterly Review of Biology, Vol. 70:141-165

Buckles, K. and D. Hungerman, (2008) "Season of Birth and Later Outcomes: Old Questions, New Answers.” mimeo, University of Norte Dame

Bobak, M. and A. Gjonca (2001) "The Seasonality of life birth is strongly influence by socio-demographic factors.” Human Reproduction, Vol. 6(17): 1512-1517

Caldwell, J. C. (1979). "Education as a factor in mortality decline: An examination of Nigerian data.” Population Studies, Vol. 33(3): 395-413

Chambers, R. (1982) "Health, Agriculture, and Rural Poverty: Why Seasons Matter." Journal of Development Studies Vol. 18(2): 217-36.

Dibley, M., Goldsby, J., Staehling, N. and F. Trowbridge (1987), “Development of normalized curves for the international growth reference: historical and technical considerations”, American Journal of Clinical Nutrition Vol. 46:736-748.

Do, T. and T. Phung, (2008) "Superstition, Fertility Timing and Human Development," mimeo, World Bank

Doblhammer, G., (2004) The Late Life Legacy of Very Early Life, Springer Verlag, Heidelberg.

Doblhammer, G. and J. Vaupel, (2001) “Lifespan Depends on Month of Birth”, Proceedings of the National Academy of Sciences of the United States of America. 98(5), 2934-2939

Duflo, E., (2003) “Grandmothers and Granddaughters: Old-Age Pensions and Intrahousehold Allocation in South Africa”, World Bank Economic Review, Vol. 17(1): 1-25. 
Elder, L., Kiess, L. and J. de Beyer (1996) Incorporating Nutrition into Project Design, Human Development Department, The World Bank

Filmer, D. and L. Pritchett, (2001), "Estimating wealth effects without expenditure data or tears: An application to educational enrollments in states of India", Demography, Vol. 38(1): 115-132

Glewwe, P. (1999). "Why does mother's schooling raise child health in developing countries: Evidence from Morocco.” Journal of Human Resources, Vol. 34(1): 124-136.

van Hanswijck de Jonge, L., Waller, G. and N. Stetter (2003) "Ethnicity modifies seasonal variation in birth weight and weight gain of infants." Journal of Nutrition, Vol. 133: 1415-1418

Holmes, J. (2006) "Do community factors have a differential impact on the health outcomes of boys and girls? Evidence from rural Pakistan" Health Policy and Planning, Vol. 21(3): 231-240.

Horton, S. (1988) "Birth Order and Child Nutritional Status: Evidence from the Philippines”, Economic Development and Cultural Change, Vol. 36(2): 341-354

Huntington, E. (1938) Season of Birth, Wiley, New York

International Institute for Population Sciences (IIPS) (2000) National Family Health Survey (NFHS-2), 1998-99: India, Mumbai: IIPS. (http://www.nfhsindia.org/india2.html)

Kabanywanyi, A., MacArthur, J., Stolk W., Habbema, J.., Mshinda, H., Bloland, P., Abdulla, S. and S. Kachur, (2008) "Malaria in pregnant women in an area with sustained high coverage of insecticide-treated bed nets", Malaria Journal, 2008, Vol.7: 133.

Kassouf A. and B. Senauer (1996) "Direct and Indirect Effects of Perental Education on Malnutrition among Children in Brazil: A Full Income Approach”, Economic Development and Cultural Change, Vol. 44(4): 817-838.

Khatiwada, N. and S. Rimal, (2007) "Assessment of Environmental Health Risks During Monsoon in Nepal”, In: Furumai, H., Kurisu, F., Katayama, H., Satoh, H., Ohgaki, S. and N. Thanh eds.) Southeast Asian Water Environment 2, IWA Publishing, London, pages 19-26.

Kihlbom, M. and S. Johansson (2004) "Month of Birth, Socioeconomic Background and Development in Swedish Men” Journal of Biosocial Science, Vol. 36: 561-571

Knodel, J. and C. Wilson, (1981) "The Secular Increase in Fecundity in German Village Populations: An Analysis of Reproductive Histories of Couples Married 17501899," Population Studies 35:53-84

Koscinski, K., Krenz-Niedbala, M. and A. Kozlowska-Rajewicz (2004) "Month-of-birth effect on height and weight in Polish rural children", American Journal of Human Biology, Vol. 16: 31-42

Kost, K., Landry D. and J. Darroch (1998) "The Effects of Pregnancy Planning Status on Birth Outcomes and Infant Care”, Family Planning Perspectives, Vol. 30(5): 223230

Lam, D. and J. Miron, (1996) "The Effect of Temperature on Human Fertility." Demography, Vol. 33(3): 291-305. , (1991) "Seasonality of birth in human populations", Social Biology, Vol. 38: $51-78$ 
Lokshin, M., Das Gupta, M. and O. Ivaschenko, (2005) “An Assessment of India's Integrated Child Development Services Nutrition Program,” Development and Change, Vol. 36(4): 613-640

Medora, N.(2003) "Mate Selection in Contemporary India" in Hamon, R. and B. Ingoldsby (ed.) Mate Selection Across Cultures, Thousand Oaks, CA: Sage Publications, pp.209-230

Mishra, V., Lahiri, S. and N. Luther (1999) Child Nutrition in India, International Institute for Population Sciences, Mumbai, India

Moestue, J. and S. Huttly (2008) “Adult education and child nutrition: the role of family and community”, Journal of Epidemiology and Community Health, Vol. 62: 153159.

Moore, S., Fulford, A., Streatfield, K., Persson, L. and A. Prentice, (2004) “Comparative analysis of patterns of survival by season of birth in rural Bangladeshi and Gambian populations”, International Journal of Epidemiology, Vol. 33: 137-143

Narasimhan, R., Retherford, R., Mishra, V., Arnold, F. and T. Roy, (1997) "Measuring the Speed of India's Fertility Decline", National Family Health Survey Bulletin, (6):1-4

Olango, P. and F. Aboud, (1990), “Determinants of mothers' treatment of diarrhea in rural Ethiopia.” Social Science and Medicine, Vol. 31: 1245-49.

Panter-Brick, C., (1996) "Proximate Determinants of Birth Seasonality and Conception Failure in Nepal," Population Studies, Vol. 50(2): 203-220

Phillips, D. and J. Young, (2000), "Birth weight, climate at birth and the risk of obesity in adult life”, International Journal of Obesity, Vol. 24: 281-287

Rajagopalan, S., Kymal, P. and P. Pei (1981) "Births, work and nutrition in Tamil Nadu, India,” in Chamber, R., Longhurst, R., Pacey, A., ed. Seasonal dimensions to rural poverty, London, Frances Pinter, pages 156-62

Rivera, J., Gonzales-Cossio, T., Flores, M., Romero, M., Rivera, M., Tellez-Rojo, M., Rosado, J. and K. Brown (2001) "Multiple micronutrient supplementation increases the growth of Mexican infants", American Journal of Clinical Nutrition, 74(5): 657-663.

Rosenzweig, M. and T. Schultz, (1982), “The behavior of mothers as inputs to child health: the determinants of birth weight, gestation, and rate of fetal growth.” in: Fuchs, V. (ed.), Economic Aspects of Health. University of Chicago Press, Chicago.

Rutstein, S. and K. Johnson, (2004), “The DHS Wealth Index”, DHS Comparative Reports No. 6. ORC Macro, Calverton, Maryland, USA.

Sahn, D., (1987), Causes and implications of seasonal variability in household food security, Food Policy Research Institute, Washington DC.

Samuelsson, U. and J. Ludvigsson, (2001) "Seasonal variation of birth month and breastfeeding in children with diabetes mellitus," Journal of Pediatric Endocrinology and Metabolism, Vol. 14(1): 43-46

Saraswathi, K. and L. Deodhar, (1990) “A Study of V. cholerae Strains Isolated in Mumbai”, Postgraduate Medicine, Vol. 36(3): 128-130.

Shephard, R., Lavallee, H., Jequier, J., LaBarre, R., Volle, M. and M. Rajic, (1979) "Season of birth and variations in stature, body mass and performance", Human Biology, Vol. 51: 299-315. 
Stock, J. and M. Yogo, (2002) “Testing for weak instruments in linear IV regression,” NBER Technical Working Paper \#284.

Subramaniam, V. (2007) "Seasonal variation in the incidence of preeclampsia and eclamsia in tropical climatic conditions." BMC Womens Health, Vol. 7(1): published online

Tanaka, H., Sei, M., Binh, T., Munakata, H., Yuasa, K. and Y. Nakahori, (2007) "Correlation of month and season of birth with height, weight and degree of obesity of rural Japanese children” Journal of Medical Investigation, Vol.54: 133139.

Thomas, D., Strauss, J. and M. Henriques, (1991) "How Does Mother's Education Affect Child Height?” Journal of Human Resources, Vol. 26(2): 183-211.

Thomas, D., (1994) "Like Father, Like Son; Like Mother, Like Daughter. Parental Resources and Child Height", Journal of Human Resources, Vol. 29(4): 950-88.

Thu, B., Schultink, W., Dillon, D., Gross, R., Leswara, D. and H. Khoi (1999) "Effect of daily and weekly micronutrient supplementation on micronutrient deficiencies and growth in young Vietnamese children”, American Journal of Clinical Nutrition, 69: 80-86.

Weber, G., Prossinger, H. and H. Seidler, (1998) "Height depends on month of birth" Nature Vol. 391: 754-755.

World Health Organization, (1995) "Physical status: the use and interpretation of anthropometry.” Geneva: WHO technical report series. , (2006) "Child growth standards: length/height-for-age, weight-for-age, weight-for-length, weight-for-height and body mass index-for-age: methods and development." Geneva: WHO.

World Bank (2002) "Ten things you never new about the World Bank", http://www.worldbank .org/tenthing/tenthings.pdf 
Table 1: Descriptive statistics for the main explanatory variables* .

\begin{tabular}{|c|c|c|c|c|c|c|}
\hline & \multicolumn{2}{|c|}{1992} & \multicolumn{2}{|c|}{1998} & \multicolumn{2}{|c|}{2005} \\
\hline & Mean & SE & Mean & SE & Mean & SE \\
\hline Male child & 0.510 & 0.004 & 0.524 & 0.003 & 0.520 & 0.003 \\
\hline Child's current age (in months) & 17.166 & 0.070 & 17.297 & 0.065 & 18.111 & 0.066 \\
\hline \multicolumn{7}{|l|}{ Birth order } \\
\hline 1st-born & 0.279 & 0.003 & 0.295 & 0.003 & 0.325 & 0.003 \\
\hline 2nd-born & 0.248 & 0.003 & 0.266 & 0.003 & 0.288 & 0.003 \\
\hline 3rd-born & 0.178 & 0.003 & 0.176 & 0.002 & 0.162 & 0.002 \\
\hline 4th-born & 0.113 & 0.002 & 0.106 & 0.002 & 0.092 & 0.002 \\
\hline 5th-born & 0.073 & 0.002 & 0.066 & 0.002 & 0.056 & 0.002 \\
\hline 6th-born & 0.047 & 0.001 & 0.042 & 0.001 & 0.033 & 0.001 \\
\hline 7th-born & 0.028 & 0.001 & 0.024 & 0.001 & 0.018 & 0.001 \\
\hline 8th-born & 0.034 & 0.001 & 0.026 & 0.001 & 0.024 & 0.001 \\
\hline Mother's current age (in years) & 26.363 & 0.039 & 25.960 & 0.034 & 26.347 & 0.034 \\
\hline Mother works & 0.246 & 0.003 & 0.284 & 0.003 & 0.262 & 0.003 \\
\hline Education of the mother (years) & 3.514 & 0.032 & 4.083 & 0.030 & 5.341 & 0.034 \\
\hline \multicolumn{7}{|l|}{ Education of the mother (category) } \\
\hline No education & 0.557 & 0.003 & 0.477 & 0.003 & 0.387 & 0.003 \\
\hline Incomplete primary & 0.158 & 0.003 & 0.094 & 0.002 & 0.071 & 0.002 \\
\hline Complete primary & 0.042 & 0.001 & 0.074 & 0.002 & 0.070 & 0.002 \\
\hline Incomplete secondary & 0.175 & 0.003 & 0.184 & 0.002 & 0.336 & 0.003 \\
\hline Complete secondary & 0.027 & 0.001 & 0.078 & 0.002 & 0.055 & 0.002 \\
\hline Higher & 0.040 & 0.001 & 0.093 & 0.002 & 0.081 & 0.002 \\
\hline Scheduled caste & 0.128 & 0.002 & 0.185 & 0.002 & 0.184 & 0.003 \\
\hline Scheduled tribe & 0.114 & 0.002 & 0.147 & 0.002 & 0.165 & 0.002 \\
\hline \multicolumn{7}{|l|}{ Religion } \\
\hline Hindu religion & 0.737 & 0.003 & 0.746 & 0.003 & 0.714 & 0.003 \\
\hline Muslim religion & 0.134 & 0.002 & 0.137 & 0.002 & 0.144 & 0.002 \\
\hline Christian religion & 0.072 & 0.002 & 0.069 & 0.002 & 0.098 & 0.002 \\
\hline Sikh religion & 0.040 & 0.001 & 0.022 & 0.001 & 0.020 & 0.001 \\
\hline Other or no religion & 0.018 & 0.001 & 0.025 & 0.001 & 0.025 & 0.001 \\
\hline Wealth index score & -0.067 & 0.007 & -0.118 & 0.006 & -0.210 & 0.006 \\
\hline Urban & 0.290 & 0.003 & 0.272 & 0.003 & 0.368 & 0.003 \\
\hline Household size & 7.971 & 0.028 & 7.516 & 0.024 & 6.823 & 0.021 \\
\hline Share of children 0 to 6 years & 0.325 & 0.001 & 0.326 & 0.001 & 0.335 & 0.001 \\
\hline Share of children 7 to 14 years & 0.125 & 0.001 & 0.115 & 0.001 & 0.105 & 0.001 \\
\hline Share of adult males & 0.243 & 0.001 & 0.250 & 0.001 & 0.246 & 0.001 \\
\hline Share of adult females & 0.243 & 0.001 & 0.250 & 0.001 & 0.246 & 0.001 \\
\hline Share of elderly & 0.036 & 0.001 & 0.034 & 0.000 & 0.032 & 0.000 \\
\hline \multicolumn{7}{|l|}{ Type of toilet } \\
\hline Flush toilet & 0.210 & 0.003 & 0.238 & 0.003 & 0.431 & 0.003 \\
\hline Latrine & 0.149 & 0.003 & 0.156 & 0.002 & 0.084 & 0.002 \\
\hline Other or none & 0.641 & 0.003 & 0.606 & 0.003 & 0.485 & 0.003 \\
\hline \multicolumn{7}{|l|}{ Source of drinking water } \\
\hline Piped water & 0.344 & 0.003 & 0.392 & 0.003 & 0.409 & 0.003 \\
\hline Well or hand pump & 0.574 & 0.003 & 0.542 & 0.003 & 0.496 & 0.003 \\
\hline Surface, river, rain, etc & 0.058 & 0.002 & 0.059 & 0.002 & 0.080 & 0.002 \\
\hline Number of observations & \multicolumn{2}{|c|}{20,260} & \multicolumn{2}{|c|}{24,837} & \multicolumn{2}{|c|}{23,105} \\
\hline
\end{tabular}

*) Sample of children younger than 36 months with non-missing HAZ and WAZ. Other explanatory variables include 36 state dummies and 11 dummies for the month of birth. 
Table 2a: Regressions of health outcomes by month of birth. Specification with the state dummies, household characteristics, characteristics of the mother, and characteristics of a child. NFHS 1992, 1998, 2005

\begin{tabular}{|c|c|c|c|c|c|c|c|c|c|}
\hline & & \multicolumn{4}{|c|}{ Height-for-Age Z-score } & \multicolumn{4}{|c|}{ Weight-for-Age Z-score } \\
\hline & & \multicolumn{2}{|c|}{ Boys } & \multicolumn{2}{|c|}{ Girls } & \multicolumn{2}{|c|}{ Boys } & \multicolumn{2}{|c|}{ Girls } \\
\hline & & Coeff. & SE & Coeff. & SE & Coeff. & SE & Coeff. & SE \\
\hline \multirow{13}{*}{$\tilde{g}$} & January & $-0.372^{* * *}$ & 0.078 & $-0.324^{* * *}$ & 0.080 & $-0.212^{* * *}$ & 0.053 & $-0.181^{* * *}$ & 0.055 \\
\hline & February & $-0.362^{* * *}$ & 0.083 & $-0.487^{* * *}$ & 0.085 & $-0.122^{* *}$ & 0.056 & $-0.175^{* * *}$ & 0.058 \\
\hline & March & $-0.489^{* * *}$ & 0.079 & $-0.364^{* * *}$ & 0.080 & $-0.166^{* * *}$ & 0.053 & $-0.228^{* * *}$ & 0.056 \\
\hline & April & $-0.281^{* * *}$ & 0.082 & $-0.410^{* * *}$ & 0.083 & $-0.140^{* *}$ & 0.055 & $-0.145^{* * *}$ & 0.056 \\
\hline & May & $-0.588^{* * *}$ & 0.082 & $-0.586^{* * *}$ & 0.084 & $-0.243^{* * *}$ & 0.055 & $-0.183^{* * *}$ & 0.057 \\
\hline & June & $-0.492^{* * *}$ & 0.079 & $-0.602^{* * *}$ & 0.079 & $-0.311^{* * *}$ & 0.053 & $-0.264^{* * *}$ & 0.055 \\
\hline & July & $-0.443^{* * *}$ & 0.075 & $-0.400^{* * *}$ & 0.077 & $-0.268^{* * *}$ & 0.051 & $-0.277^{* * *}$ & 0.054 \\
\hline & August & $-0.311^{* * *}$ & 0.073 & $-0.253^{* * *}$ & 0.073 & $-0.233^{* * *}$ & 0.050 & $-0.189^{* * *}$ & 0.052 \\
\hline & September & $-0.222^{* * *}$ & 0.076 & $-0.208^{* * *}$ & 0.078 & $-0.115^{* *}$ & 0.052 & $-0.188^{* * *}$ & 0.054 \\
\hline & October & $-0.126^{*}$ & 0.072 & -0.074 & 0.073 & $-0.127^{* * *}$ & 0.049 & -0.071 & 0.051 \\
\hline & November & -0.072 & 0.075 & 0.020 & 0.076 & -0.078 & 0.051 & 0.024 & 0.053 \\
\hline & December & \multicolumn{8}{|c|}{ Reference month } \\
\hline & N Obs. & \multirow{2}{*}{\multicolumn{2}{|c|}{$\begin{array}{l}10,341 \\
0,167\end{array}$}} & \multirow{2}{*}{\multicolumn{2}{|c|}{$\begin{array}{l}9,946 \\
0.181\end{array}$}} & \multirow{2}{*}{\multicolumn{2}{|c|}{$\begin{array}{c}13,725 \\
0.170\end{array}$}} & \multirow{2}{*}{\multicolumn{2}{|c|}{$\begin{array}{c}13,284 \\
0.158\end{array}$}} \\
\hline & $\mathrm{R}^{2}$ & & & & & & & & \\
\hline \multirow{11}{*}{$\stackrel{g}{g}$} & January & $-0.399^{* * *}$ & 0.065 & $-0.433^{* * *}$ & 0.068 & $-0.197^{* * * *}$ & 0.052 & $-0.309^{* * *}$ & 0.055 \\
\hline & February & $-0.537^{* * *}$ & 0.069 & $-0.432^{* * *}$ & 0.071 & $-0.356^{* * *}$ & 0.055 & $-0.292^{* * *}$ & 0.057 \\
\hline & March & $-0.590^{* * *}$ & 0.065 & $-0.606^{* * *}$ & 0.068 & $-0.370^{* * *}$ & 0.052 & $-0.418^{* * *}$ & 0.054 \\
\hline & April & $-0.611^{* * *}$ & 0.067 & $-0.654^{* * *}$ & 0.071 & $-0.373^{* * *}$ & 0.053 & $-0.553^{* * *}$ & 0.056 \\
\hline & May & $-0.605^{* * *}$ & 0.066 & $-0.541^{* * *}$ & 0.069 & $-0.372^{* * *}$ & 0.052 & $-0.424^{* * *}$ & 0.055 \\
\hline & June & $-0.597^{* * *}$ & 0.063 & $-0.529^{* * *}$ & 0.067 & $-0.311^{* * *}$ & 0.050 & $-0.363^{* * *}$ & 0.054 \\
\hline & July & $-0.524^{* * *}$ & 0.063 & $-0.595^{* * *}$ & 0.066 & $-0.300^{* * *}$ & 0.050 & $-0.387^{* * *}$ & 0.053 \\
\hline & August & $-0.443^{* * *}$ & 0.060 & $-0.422^{* * *}$ & 0.062 & $-0.237^{* * *}$ & 0.048 & $-0.302^{* * *}$ & 0.050 \\
\hline & September & $-0.254^{* * *}$ & 0.062 & $-0.376^{* * *}$ & 0.064 & $-0.110^{* *}$ & 0.049 & $-0.219^{* * *}$ & 0.051 \\
\hline & October & $-0.261^{* * *}$ & 0.060 & $-0.183^{* * *}$ & 0.062 & $-0.117^{* *}$ & 0.047 & -0.067 & 0.050 \\
\hline & November & $-0.112^{*}$ & 0.061 & $-0.205^{* * *}$ & 0.064 & 0.003 & 0.049 & -0.070 & 0.051 \\
\hline & December & \multicolumn{8}{|c|}{ Reference month } \\
\hline & N Obs. & \multirow{2}{*}{\multicolumn{2}{|c|}{$\begin{array}{c}13,023 \\
0.190\end{array}$}} & \multirow{2}{*}{\multicolumn{2}{|c|}{$\begin{array}{c}11,818 \\
0.228\end{array}$}} & \multirow{2}{*}{\multicolumn{2}{|c|}{$\begin{array}{c}13,023 \\
0202\end{array}$}} & \multirow{2}{*}{\multicolumn{2}{|c|}{$\begin{array}{c}11,818 \\
0.231\end{array}$}} \\
\hline & $\mathrm{R}^{2}$ & & & & & & & & \\
\hline \multirow{14}{*}{ ํㅗㅇ } & January & $-0.171^{* *}$ & 0.066 & -0.080 & 0.072 & $-0.146^{* * *}$ & 0.050 & 0.036 & 0.054 \\
\hline & February & $-0.209^{* * *}$ & 0.071 & $-0.352^{* * *}$ & 0.074 & $-0.168^{* * *}$ & 0.053 & $-0.152^{* * *}$ & 0.055 \\
\hline & March & $-0.287^{* * *}$ & 0.068 & $-0.328^{* * *}$ & 0.071 & $-0.231^{* * *}$ & 0.051 & $-0.139^{* * *}$ & 0.053 \\
\hline & April & $-0.423^{* * *}$ & 0.066 & $-0.431^{* * *}$ & 0.073 & $-0.305^{* * *}$ & 0.050 & $-0.250^{* * *}$ & 0.054 \\
\hline & May & $-0.380^{* * *}$ & 0.068 & $-0.347^{* * *}$ & 0.073 & $-0.257^{* * *}$ & 0.051 & $-0.215^{* * *}$ & 0.055 \\
\hline & June & $-0.405^{* * *}$ & 0.067 & $-0.457^{* * *}$ & 0.070 & $-0.302^{* * *}$ & 0.050 & $-0.337^{* * *}$ & 0.053 \\
\hline & July & $-0.274^{* * *}$ & 0.066 & $-0.392^{* * *}$ & 0.071 & $-0.220^{* * *}$ & 0.049 & $-0.160^{* * *}$ & 0.053 \\
\hline & August & $-0.286^{* * *}$ & 0.061 & $-0.353^{* * *}$ & 0.066 & $-0.211^{* * *}$ & 0.046 & $-0.144^{* * *}$ & 0.049 \\
\hline & September & $-0.285^{* * *}$ & 0.064 & $-0.196^{* * *}$ & 0.068 & $-0.201^{* * *}$ & 0.048 & -0.016 & 0.051 \\
\hline & October & -0.089 & 0.061 & $-0.126^{*}$ & 0.065 & -0.043 & 0.046 & 0.024 & 0.049 \\
\hline & November & 0.011 & 0.062 & $-0.170^{* * *}$ & 0.065 & -0.011 & 0.047 & -0.016 & 0.049 \\
\hline & December & \multicolumn{8}{|c|}{ Reference month } \\
\hline & N Obs. & \multirow{2}{*}{\multicolumn{2}{|c|}{$\begin{array}{c}12,020 \\
0.143\end{array}$}} & \multirow{2}{*}{\multicolumn{2}{|c|}{$\begin{array}{c}11,085 \\
0.156\end{array}$}} & 12 & & & \\
\hline & $\mathrm{R}^{2}$ & & & & & 0.2 & & 0.2 & \\
\hline
\end{tabular}

Note: ${ }^{*}$ is significant at $10 \%$ level; ${ }^{* *}$ is significant at $5 \%$ level; ${ }^{* * *}$ is significant at $1 \%$ level. 
Table 2b: Regressions of health outcomes by month of birth. Specification with the state dummies, household characteristics, characteristics of the mother, characteristics of a child and local infrastructure characteristics.

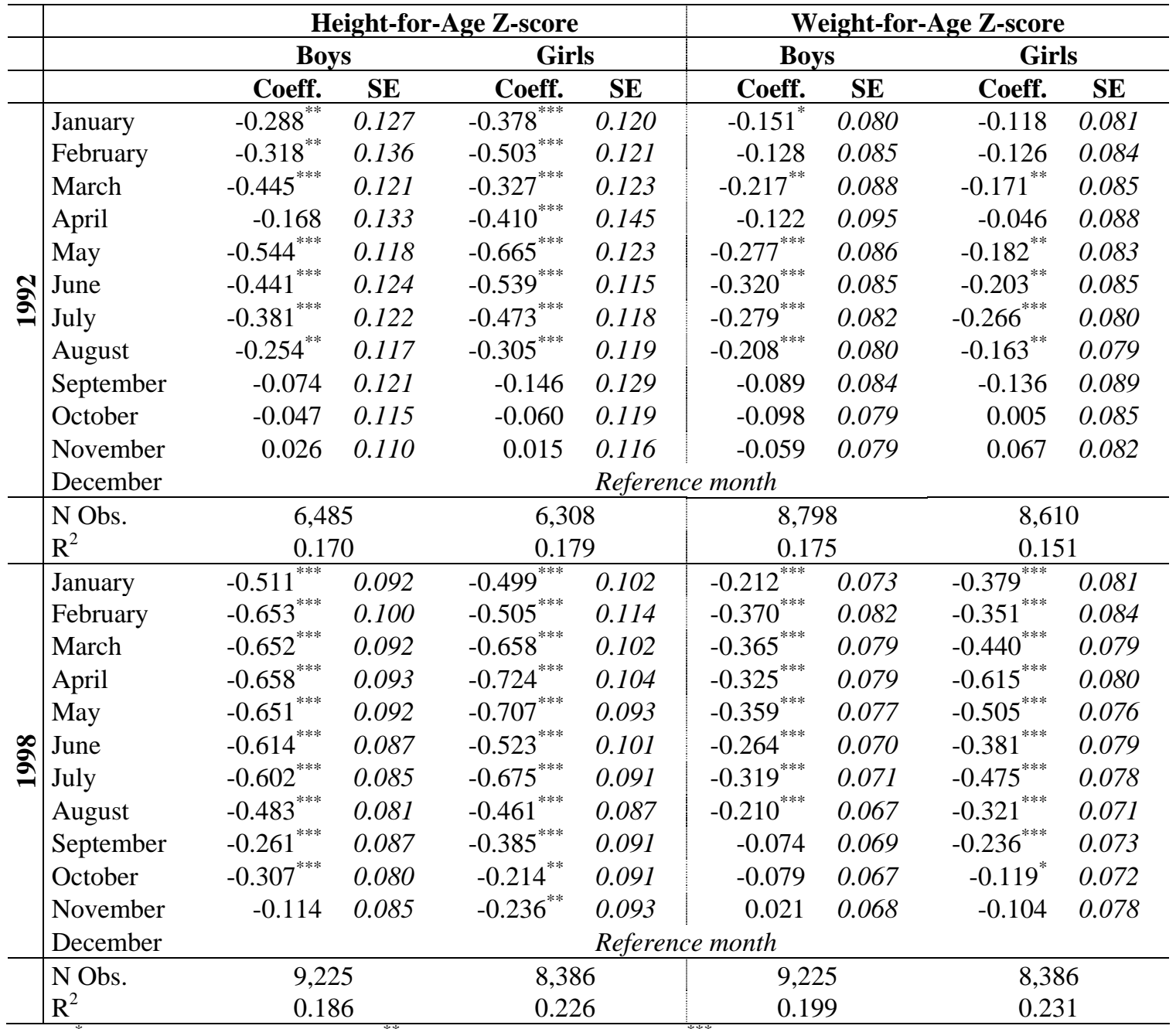

Note: ${ }^{*}$ is significant at $10 \%$ level; ${ }^{* *}$ is significant at $5 \%$ level; ${ }^{* * *}$ is significant at $1 \%$ level. Standard errors are adjusted for clustering on a village level. 
Table 2c: Fixed effects regressions of health outcomes by month of birth. Sample of households with two or more children younger than 3 years of age.

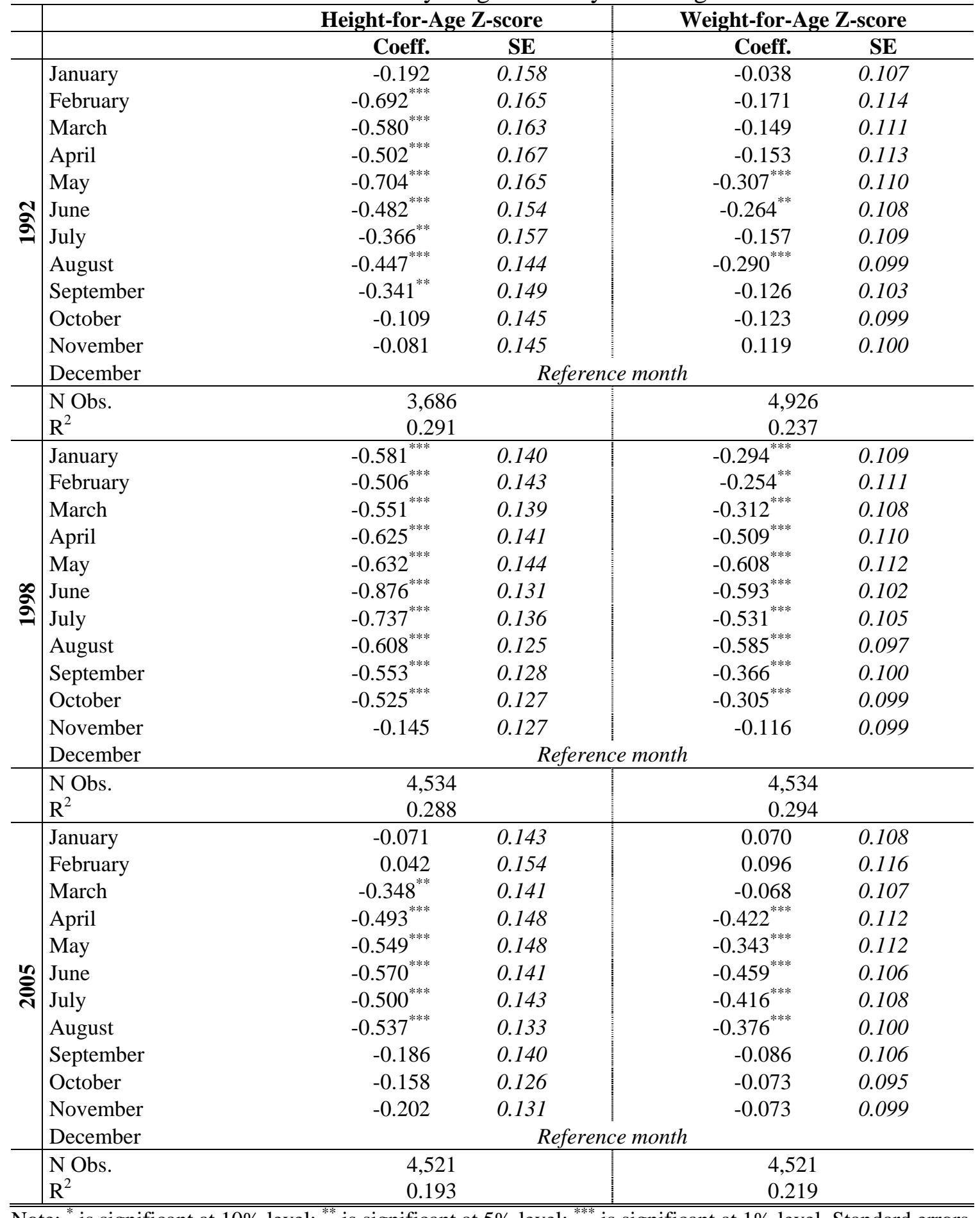

Note: ${ }^{*}$ is significant at $10 \%$ level; ${ }^{* *}$ is significant at $5 \%$ level; ${ }^{* * *}$ is significant at $1 \%$ level. Standard errors are adjusted for clustering on a village level. 
Table 3: Tests of the joint significance of coefficients on the interactions of household wealth and maternal education with the month of birth in HAZ and WAZ regressions. Ftest for Specification 1 and 2 and $\chi^{2}$-test for Specification 3.

\begin{tabular}{|c|c|c|c|c|c|c|}
\hline & & \multicolumn{2}{|c|}{ Specification 1} & \multicolumn{2}{|c|}{ Specification 2} & \multirow{2}{*}{$\begin{array}{c}\text { Specification } 3 \\
\text { Boys \& Girls }\end{array}$} \\
\hline & & Boys & Girls & Boys & Girls & \\
\hline \multirow{12}{*}{ 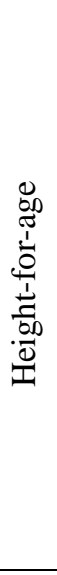 } & Wealth & & & & & \\
\hline & 1992 & $2.313^{* * *}$ & $1.992^{* *}$ & 1.263 & 1.353 & $21.476^{* *}$ \\
\hline & 1998 & $2.944^{* * *}$ & $3.478^{* * *}$ & 1.467 & $1.890^{* *}$ & $36.454^{* * *}$ \\
\hline & 2005 & $3.091^{* * *}$ & $2.070^{* *}$ & - & - & 15.274 \\
\hline & Educati & & & & & \\
\hline & 1992 & 1.457 & $1.922^{* *}$ & $1.582^{*}$ & $1.689^{*}$ & $27.169^{* * *}$ \\
\hline & 1998 & $3.156^{* * *}$ & $2.595^{* * *}$ & $2.395^{* * *}$ & $1.641^{*}$ & $19.100^{*}$ \\
\hline & 2005 & $2.818^{* * *}$ & $2.584^{* * *}$ & - & - & 15.654 \\
\hline & Wealth & & & & & \\
\hline & 1992 & $1.794^{* *}$ & $1.664^{* *}$ & 1.359 & 1.351 & $35.285^{* *}$ \\
\hline & 1998 & $2.350^{* * *}$ & $2.458^{* * *}$ & $1.589^{* *}$ & $1.565^{* *}$ & $45.753^{* * *}$ \\
\hline & 2005 & $2.463^{* * *}$ & $2.632^{* * *}$ & - & - & $32.968^{*}$ \\
\hline \multirow{12}{*}{ 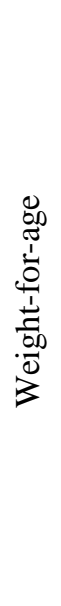 } & Wealth & & & & & \\
\hline & 1992 & 1.003 & 1.538 & 0.834 & 1.398 & 16.472 \\
\hline & 1998 & $2.593^{* * *}$ & 1.549 & $2.229^{* *}$ & 0.988 & $21.896^{* *}$ \\
\hline & 2005 & 1.504 & $1.986^{* *}$ & - & - & 14.435 \\
\hline & Educati & & & & & \\
\hline & 1992 & 0.895 & 0.891 & 1.214 & 1.206 & $21.240^{* *}$ \\
\hline & 1998 & $3.073^{* * *}$ & $1.608^{*}$ & $2.104^{* *}$ & 1.461 & 13.449 \\
\hline & 2005 & $2.156^{* *}$ & $2.230^{* *}$ & - & - & $18.252^{*}$ \\
\hline & Wealth & & & & & \\
\hline & 1992 & 0.929 & 1.244 & 1.067 & 1.070 & 29.716 \\
\hline & 1998 & $2.149^{* * * *}$ & $1.499^{*}$ & $1.699^{* *}$ & 1.348 & $35.632^{* *}$ \\
\hline & 2005 & 1.313 & $2.141^{* * *}$ & - & - & $45.764^{* * *}$ \\
\hline
\end{tabular}

$\overline{\text { Note: }} \overline{{ }^{*} \text { is significant at } 10 \% \text { level; }{ }^{* *} \text { is significant at } 5 \%} \overline{\overline{\text { level; }{ }^{* * *} \text { is significant at } 1 \%}} \overline{\overline{\text { level. Standard errors }}}$ are adjusted for clustering on a village level. 
Table 4: MLogit of the probability of a child to be born in a certain month of the year. Coefficients on household wealth and maternal education variables.

\begin{tabular}{|c|c|c|c|c|c|c|c|c|c|c|c|c|}
\hline & \multicolumn{2}{|c|}{1992 Boys } & \multicolumn{2}{|c|}{1992 Girls } & \multicolumn{2}{|c|}{1998 Boys } & \multicolumn{2}{|c|}{1998 Girls } & \multicolumn{2}{|c|}{2005 Boys } & \multicolumn{2}{|c|}{2005 Girls } \\
\hline & Coeff. & SE & Coeff. & SE & Coeff. & SE & Coeff. & SE & Coeff. & SE & Coeff. & SE \\
\hline & \multicolumn{12}{|c|}{ Household wealth index } \\
\hline January & 0.113 & 0.086 & -0.011 & 0.086 & 0.069 & 0.085 & -0.114 & 0.090 & -0.012 & 0.085 & -0.010 & 0.089 \\
\hline February & $0.161^{*}$ & 0.092 & -0.155 & 0.092 & 0.127 & 0.090 & -0.005 & 0.093 & 0.073 & 0.089 & -0.167 & 0.091 \\
\hline March & 0.120 & 0.088 & -0.097 & 0.089 & 0.108 & 0.088 & -0.056 & 0.091 & 0.125 & 0.087 & -0.032 & 0.088 \\
\hline April & 0.147 & 0.090 & -0.030 & 0.090 & 0.066 & 0.089 & 0.048 & 0.095 & -0.078 & 0.086 & -0.025 & 0.090 \\
\hline May & $0.163^{*}$ & 0.091 & -0.018 & 0.090 & $0.180^{* *}$ & 0.088 & -0.051 & 0.092 & -0.011 & 0.087 & 0.042 & 0.090 \\
\hline June & $0.189^{* *}$ & 0.088 & -0.058 & 0.090 & 0.082 & 0.086 & -0.076 & 0.090 & 0.133 & 0.086 & 0.085 & 0.087 \\
\hline July & $0.230^{* * *}$ & 0.086 & -0.055 & 0.087 & 0.084 & 0.084 & 0.053 & 0.088 & 0.088 & 0.085 & 0.024 & 0.088 \\
\hline August & 0.097 & 0.084 & -0.069 & 0.083 & $0.217^{* * *}$ & 0.081 & -0.016 & 0.085 & 0.042 & 0.081 & -0.028 & 0.084 \\
\hline September & $0.147^{*}$ & 0.086 & -0.095 & 0.088 & 0.032 & 0.083 & -0.086 & 0.088 & 0.110 & 0.082 & -0.058 & 0.086 \\
\hline October & $0.332^{* * *}$ & 0.083 & -0.095 & 0.083 & $0.192^{* *}$ & 0.081 & -0.034 & 0.085 & -0.018 & 0.081 & 0.073 & 0.083 \\
\hline November & 0.085 & 0.085 & -0.094 & 0.085 & $0.186^{* *}$ & 0.083 & 0.010 & 0.086 & -0.043 & 0.081 & -0.070 & 0.084 \\
\hline December & \multirow{2}{*}{\multicolumn{4}{|c|}{$22313^{* *}$}} & \multicolumn{4}{|c|}{ Reference Month } & & & & \\
\hline \multirow[t]{2}{*}{ LR Test } & & & 5.5 & & 15.5 & & 6.8 & & \multicolumn{2}{|c|}{14.449} & \multicolumn{2}{|c|}{12.354} \\
\hline & \multicolumn{12}{|c|}{ Education of the mother } \\
\hline January & -0.012 & 0.013 & -0.006 & 0.013 & -0.002 & 0.012 & 0.004 & 0.013 & 0.005 & 0.012 & -0.001 & 0.013 \\
\hline February & $-0.012^{*}$ & 0.014 & 0.003 & 0.013 & -0.012 & 0.013 & -0.001 & 0.014 & -0.004 & 0.012 & 0.020 & 0.013 \\
\hline March & -0.019 & 0.013 & -0.004 & 0.013 & -0.015 & 0.013 & -0.011 & 0.013 & -0.011 & 0.012 & 0.020 & 0.013 \\
\hline April & -0.022 & 0.013 & -0.003 & 0.013 & -0.003 & 0.013 & -0.009 & 0.014 & 0.006 & 0.012 & 0.010 & 0.013 \\
\hline May & $-0.017^{*}$ & 0.013 & -0.019 & 0.013 & $-0.024^{* *}$ & 0.013 & 0.012 & 0.013 & 0.002 & 0.012 & 0.011 & 0.013 \\
\hline June & $0.003^{* *}$ & 0.013 & -0.019 & 0.013 & -0.017 & 0.012 & -0.003 & 0.013 & -0.006 & 0.012 & 0.009 & 0.013 \\
\hline July & $-0.023^{* * *}$ & 0.013 & -0.016 & 0.013 & -0.003 & 0.012 & 0.006 & 0.013 & -0.011 & 0.012 & 0.002 & 0.013 \\
\hline August & -0.018 & 0.012 & -0.015 & 0.012 & $-0.024^{* * *}$ & 0.012 & -0.006 & 0.012 & -0.000 & 0.011 & 0.013 & 0.012 \\
\hline September & $-0.008^{*}$ & 0.013 & -0.016 & 0.013 & 0.009 & 0.012 & 0.004 & 0.013 & 0.007 & 0.012 & 0.024 & 0.012 \\
\hline October & $-0.012^{* * *}$ & 0.012 & -0.018 & 0.012 & $-0.024^{* *}$ & 0.012 & 0.000 & 0.012 & 0.007 & 0.011 & -0.000 & 0.012 \\
\hline November & 0.003 & 0.012 & 0.009 & 0.012 & $-0.013^{* *}$ & 0.012 & 0.000 & 0.013 & 0.003 & 0.011 & 0.006 & 0.012 \\
\hline December & \multicolumn{12}{|c|}{ Reference Month } \\
\hline LR Test & \multicolumn{2}{|c|}{11.918} & \multicolumn{2}{|c|}{12.032} & 17.6 & & \multicolumn{2}{|c|}{4.625} & \multicolumn{2}{|c|}{6.230} & \multicolumn{2}{|c|}{9.471} \\
\hline
\end{tabular}

Note: ${ }^{*}$ is significant at $10 \%$ level; ${ }^{* *}$ is significant at $5 \%$ level; ${ }^{* * *}$ is significant at $1 \%$ level. Standard errors are adjusted for clustering on a village level. 
Table 5. Distribution of mother's assessment of the weight of her child at birth.

\begin{tabular}{lcccc}
\hline & \multicolumn{2}{c}{ Boys } & \multicolumn{2}{c}{ Girls } \\
\hline $\mathbf{1 9 9 2}$ & Mean & SE & Mean & SE \\
Larger than average & & & & \\
Average & 0.125 & 0.003 & 0.142 & 0.003 \\
Smaller than average & 0.635 & 0.004 & 0.650 & 0.004 \\
$\mathbf{1 9 9 8}$ & 0.239 & 0.004 & 0.208 & 0.004 \\
Larger than average & & & & \\
Average & 0.128 & 0.003 & 0.151 & 0.003 \\
Smaller than average & 0.610 & 0.005 & 0.621 & 0.004 \\
Very small & 0.210 & 0.004 & 0.181 & 0.003 \\
2005 & 0.053 & 0.002 & 0.048 & 0.002 \\
Very large & & & & \\
Larger than average & 0.040 & 0.002 & 0.043 & 0.002 \\
Average & 0.187 & 0.004 & 0.192 & 0.004 \\
Smaller than average & 0.534 & 0.005 & 0.552 & 0.005 \\
Very small & 0.165 & 0.004 & 0.152 & 0.004 \\
& 0.075 & 0.003 & 0.061 & 0.002 \\
\hline
\end{tabular}


Table 6: Probit estimates of probability of survival till age of one, sample of children born within 36 months prior to the date of interview. Coefficients on the interactions of moth-of-birth dummies and the dummy of being born small.

\begin{tabular}{|c|c|c|c|c|c|c|c|c|c|c|c|c|}
\hline & \multicolumn{2}{|c|}{1992 Boys } & \multicolumn{2}{|c|}{1992 Girls } & \multicolumn{2}{|c|}{1998 Boys } & \multicolumn{2}{|c|}{1998 Girls } & \multicolumn{2}{|c|}{2005 Boys } & \multicolumn{2}{|c|}{2005 Girls } \\
\hline & Coeff. & SE & Coeff. & SE & Coeff. & SE & Coeff. & SE & Coeff. & SE & Coeff. & SE \\
\hline & \multicolumn{12}{|c|}{ Interactions of month-of-birth dummies and weight at birth } \\
\hline January & -0.182 & 0.196 & 0.173 & 0.195 & $0.401^{*}$ & 0.212 & -0.326 & 0.217 & $-0.442^{*}$ & 0.251 & -0.427 & 0.269 \\
\hline February & -0.227 & 0.205 & -0.270 & 0.201 & 0.390 & 0.239 & -0.182 & 0.226 & 0.122 & 0.267 & 0.056 & 0.270 \\
\hline March & -0.235 & 0.202 & 0.096 & 0.206 & -0.022 & 0.212 & 0.188 & 0.243 & -0.092 & 0.255 & 0.010 & 0.265 \\
\hline April & -0.289 & 0.201 & 0.163 & 0.202 & 0.249 & 0.221 & $-0.566^{* *}$ & 0.226 & 0.003 & 0.284 & 0.265 & 0.295 \\
\hline May & -0.273 & 0.206 & 0.064 & 0.202 & 0.293 & 0.211 & $-0.403^{*}$ & 0.216 & -0.068 & 0.267 & -0.379 & 0.260 \\
\hline June & -0.057 & 0.203 & 0.177 & 0.197 & 0.276 & 0.214 & -0.058 & 0.225 & -0.127 & 0.253 & -0.090 & 0.262 \\
\hline July & $-0.524^{* * *}$ & 0.196 & 0.166 & 0.197 & 0.059 & 0.205 & -0.318 & 0.213 & $-0.461^{*}$ & 0.243 & $-0.474^{*}$ & 0.258 \\
\hline August & -0.283 & 0.188 & -0.077 & 0.184 & -0.045 & 0.190 & -0.116 & 0.203 & -0.194 & 0.231 & $-0.499^{* *}$ & 0.242 \\
\hline September & -0.291 & 0.198 & 0.173 & 0.187 & 0.138 & 0.207 & -0.071 & 0.206 & -0.288 & 0.235 & -0.012 & 0.281 \\
\hline October & $-0.391^{* *}$ & 0.186 & 0.104 & 0.186 & 0.216 & 0.198 & -0.289 & 0.201 & -0.352 & 0.237 & 0.115 & 0.249 \\
\hline November & -0.228 & 0.192 & 0.183 & 0.187 & 0.041 & 0.189 & -0.028 & 0.203 & -0.034 & 0.236 & -0.133 & 0.245 \\
\hline December & \multicolumn{12}{|c|}{ Reference Month } \\
\hline N Obs. & \multicolumn{2}{|c|}{12,531} & \multicolumn{2}{|c|}{11,889} & 11, & & \multicolumn{2}{|c|}{10,520} & \multicolumn{2}{|c|}{10,323} & \multicolumn{2}{|c|}{9,196} \\
\hline
\end{tabular}

Note: ${ }^{*}$ is significant at $10 \%$ level; ${ }^{* *}$ is significant at $5 \%$ level; ${ }^{* * *}$ is significant at $1 \%$ level. Standard errors are adjusted for clustering on a village level. 
Table 7. Distribution of the answer to the question about "desirability" of a child.

\begin{tabular}{lcccc}
\hline & \multicolumn{2}{c}{ Boys } & \multicolumn{2}{c}{ Girls } \\
\hline $\mathbf{1 9 9 2}$ & Mean & SE & Mean & SE \\
Wanted now & & & & \\
Wanted later & 0.753 & 0.004 & 0.792 & 0.004 \\
Wanted no more children & 0.149 & 0.003 & 0.127 & 0.003 \\
$\mathbf{1 9 9 8}$ & 0.098 & 0.003 & 0.081 & 0.002 \\
Wanted now & & & & \\
Wanted later & 0.783 & 0.004 & 0.812 & 0.004 \\
Wanted no more children & 0.117 & 0.003 & 0.101 & 0.003 \\
$\mathbf{2 0 0 5}$ & 0.100 & 0.003 & 0.087 & 0.003 \\
Wanted now & & & & \\
Wanted later & 0.778 & 0.004 & 0.799 & 0.004 \\
Wanted no more children & 0.109 & 0.003 & 0.094 & 0.003 \\
\hline \hline
\end{tabular}


Table 8: MLogit and IV MLogit estimations of the probability to be born in a certain month as a function of "child desirability". Coefficients on "desirability" variable.

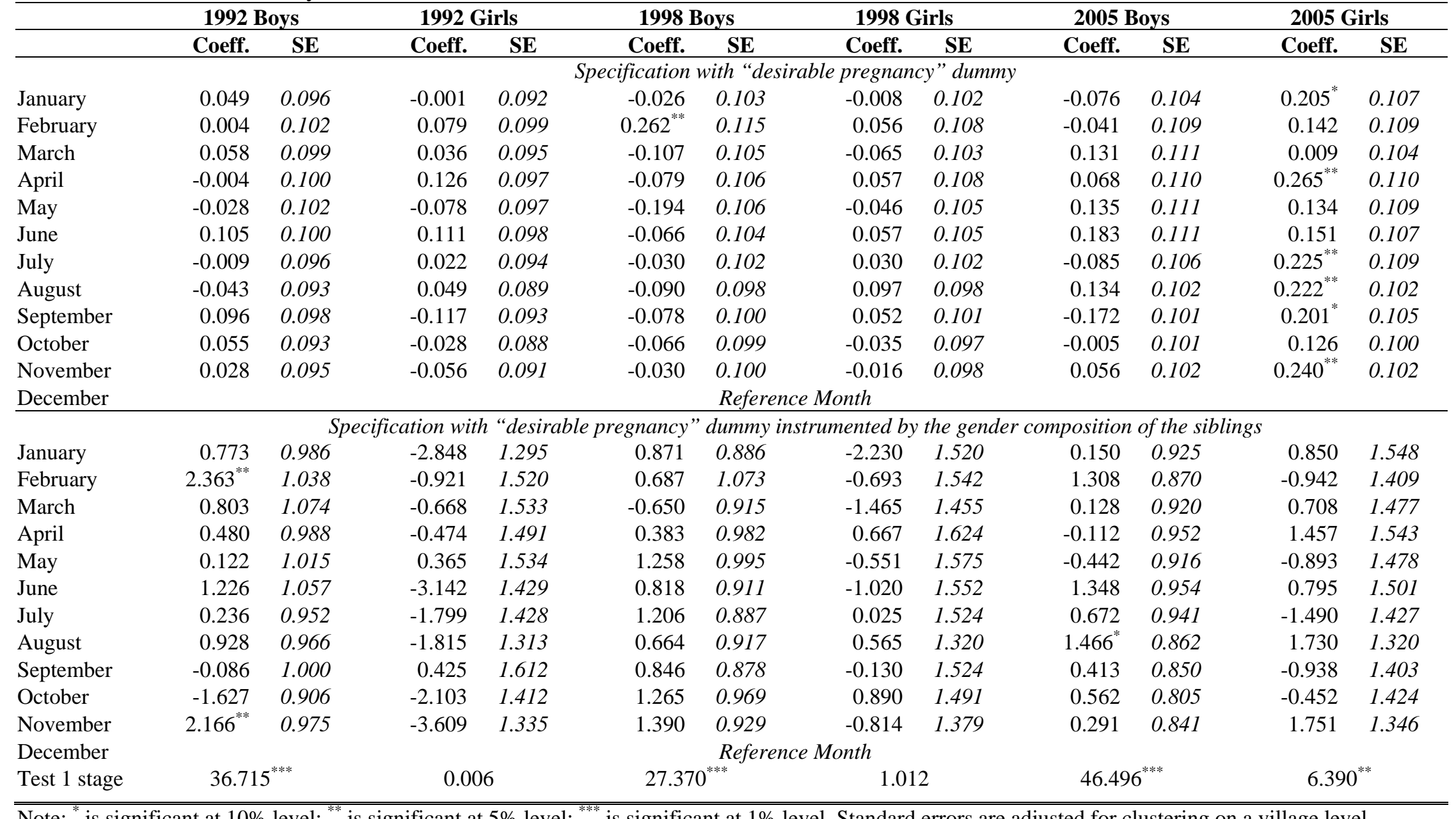

Note: ${ }^{*}$ is significant at $10 \%$ level; ${ }^{* *}$ is significant at $5 \%$ level; ${ }^{* * *}$ is significant at $1 \%$ level. Standard errors are adjusted for clustering on a village level. 

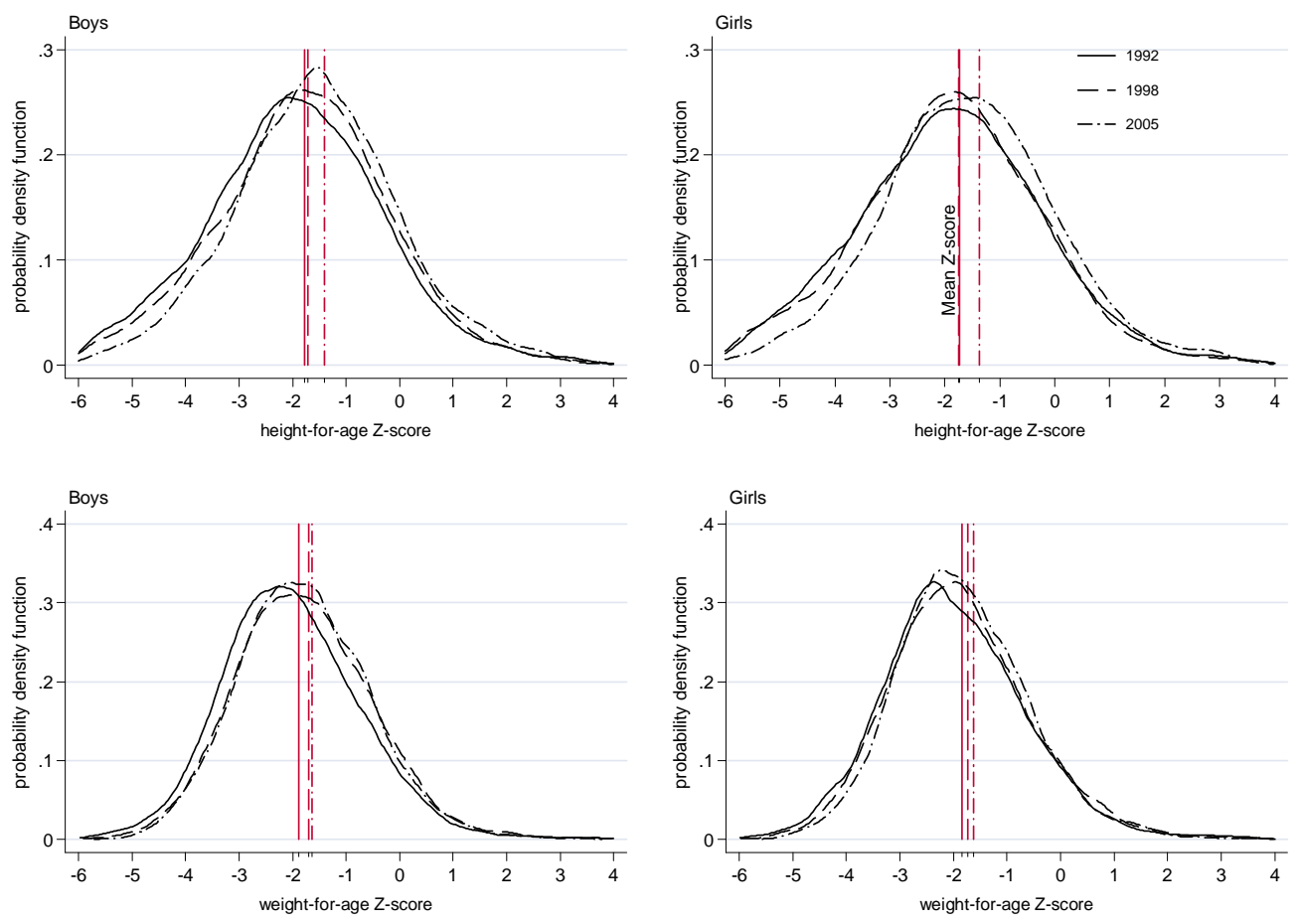

Figure 1: Distribution of WAZ and HAZ by gender and for three waves of NFHS. Kernel density estimations. 

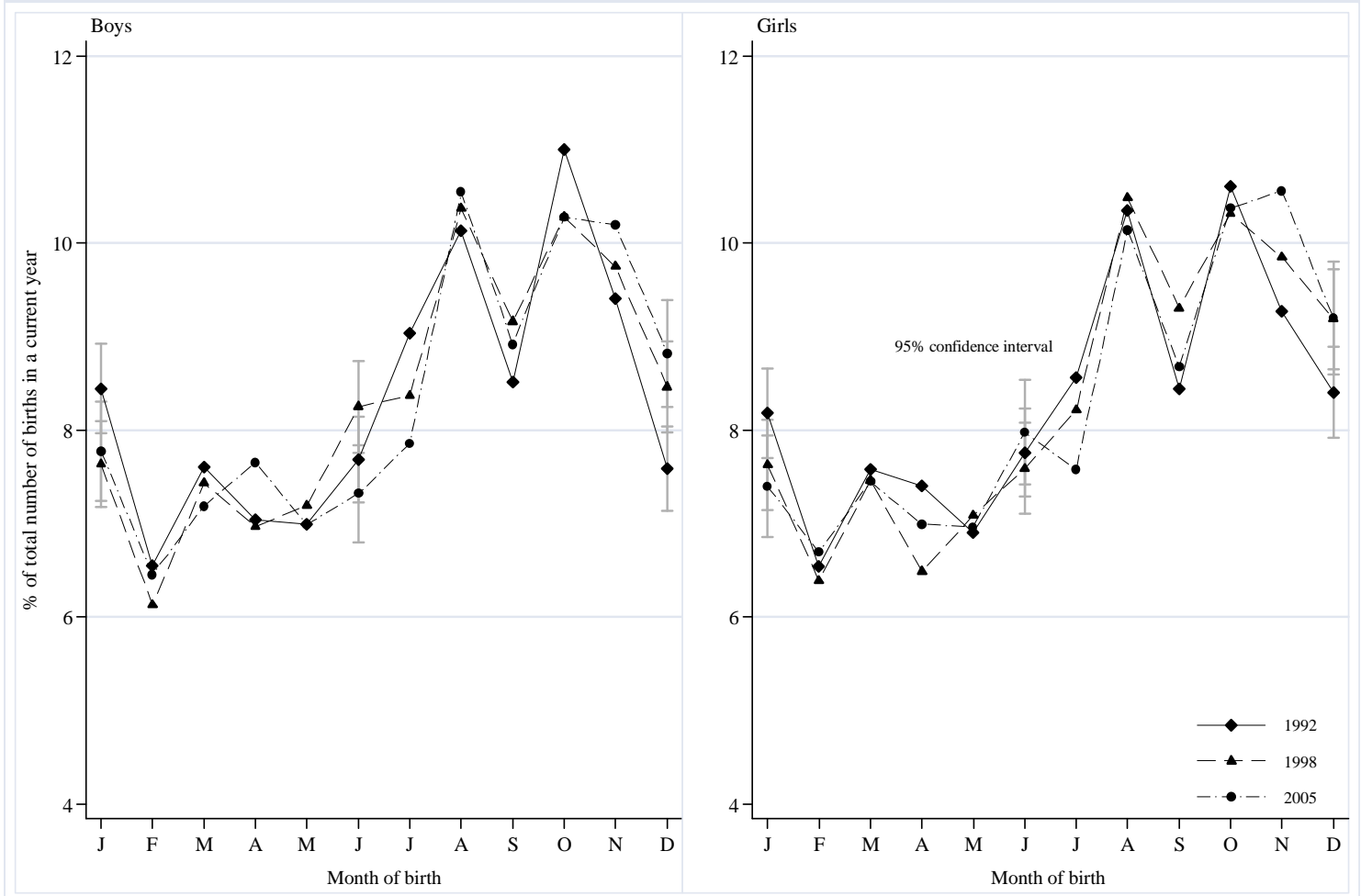

Figure 2: Share of the total number of births in a current year by month of birth. India NFHS 1992, 1998, 2005

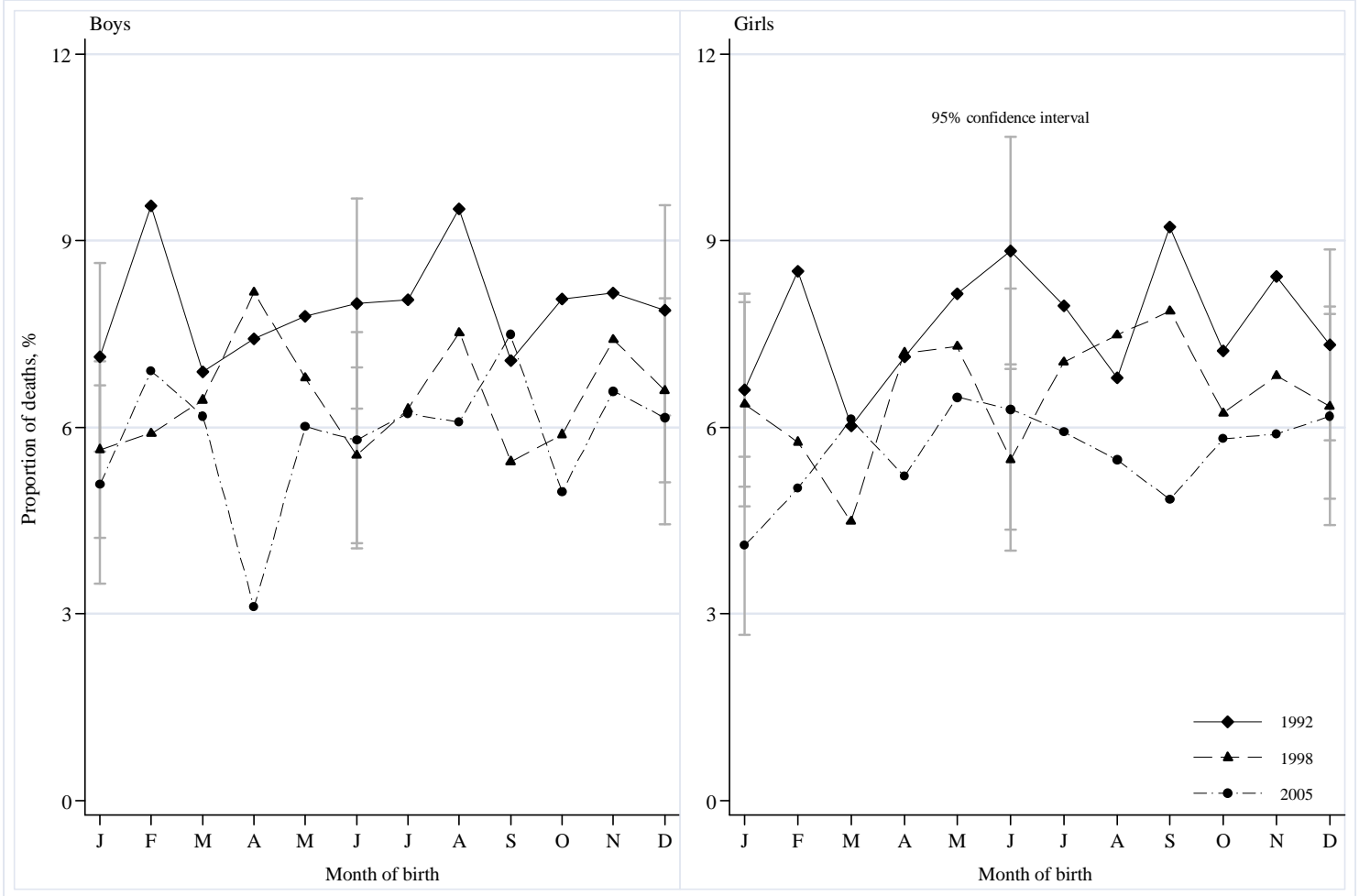

Figure 3: Proportion of children who died before the age of 36 months among all children born in a particular month. India NFHS 1992, 1998, 2005 

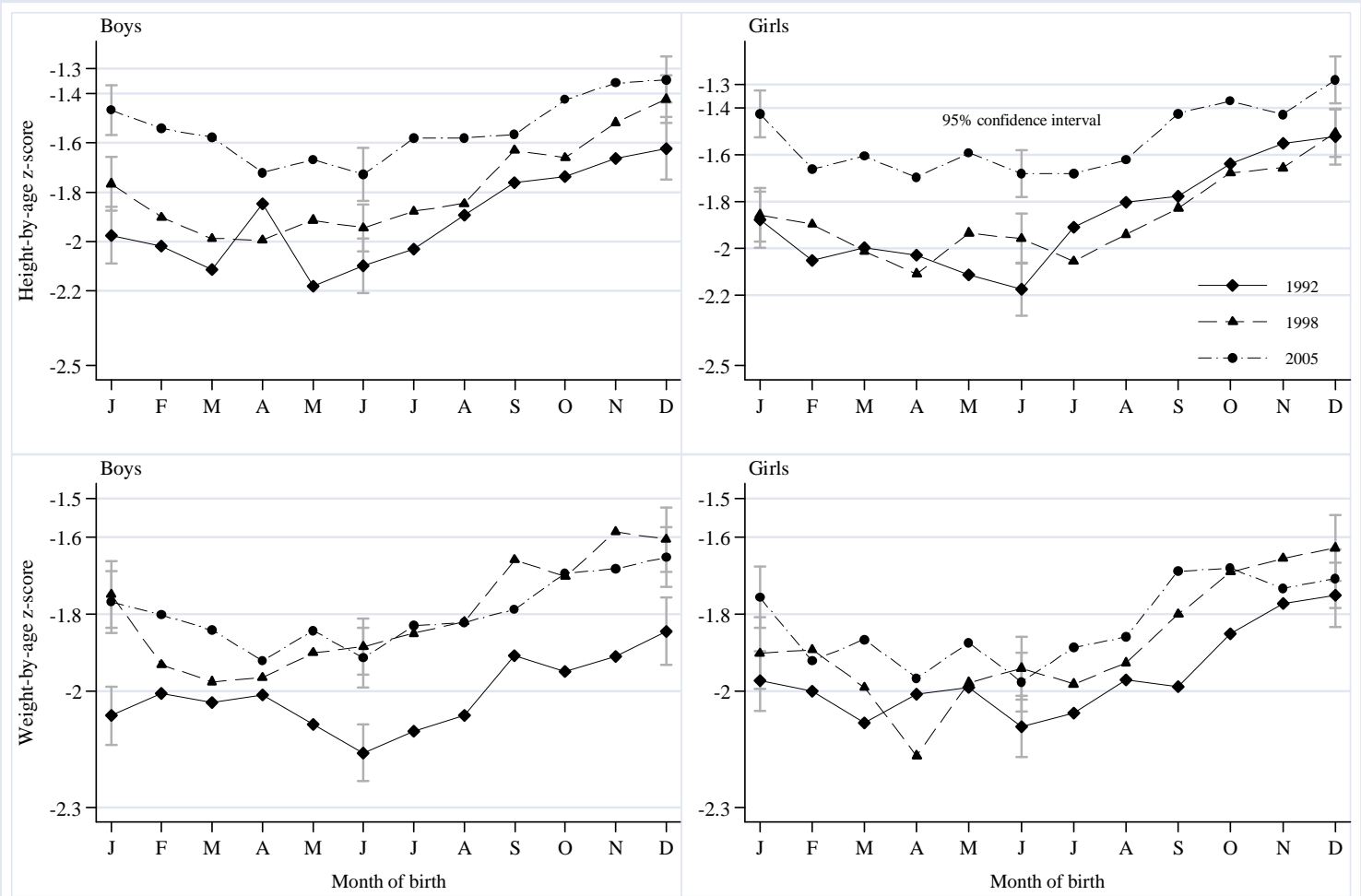

Figure 4: Health outcomes (WAZ and HAZ) by month of birth and gender.

India NFHS 1992, 1998 and 2005
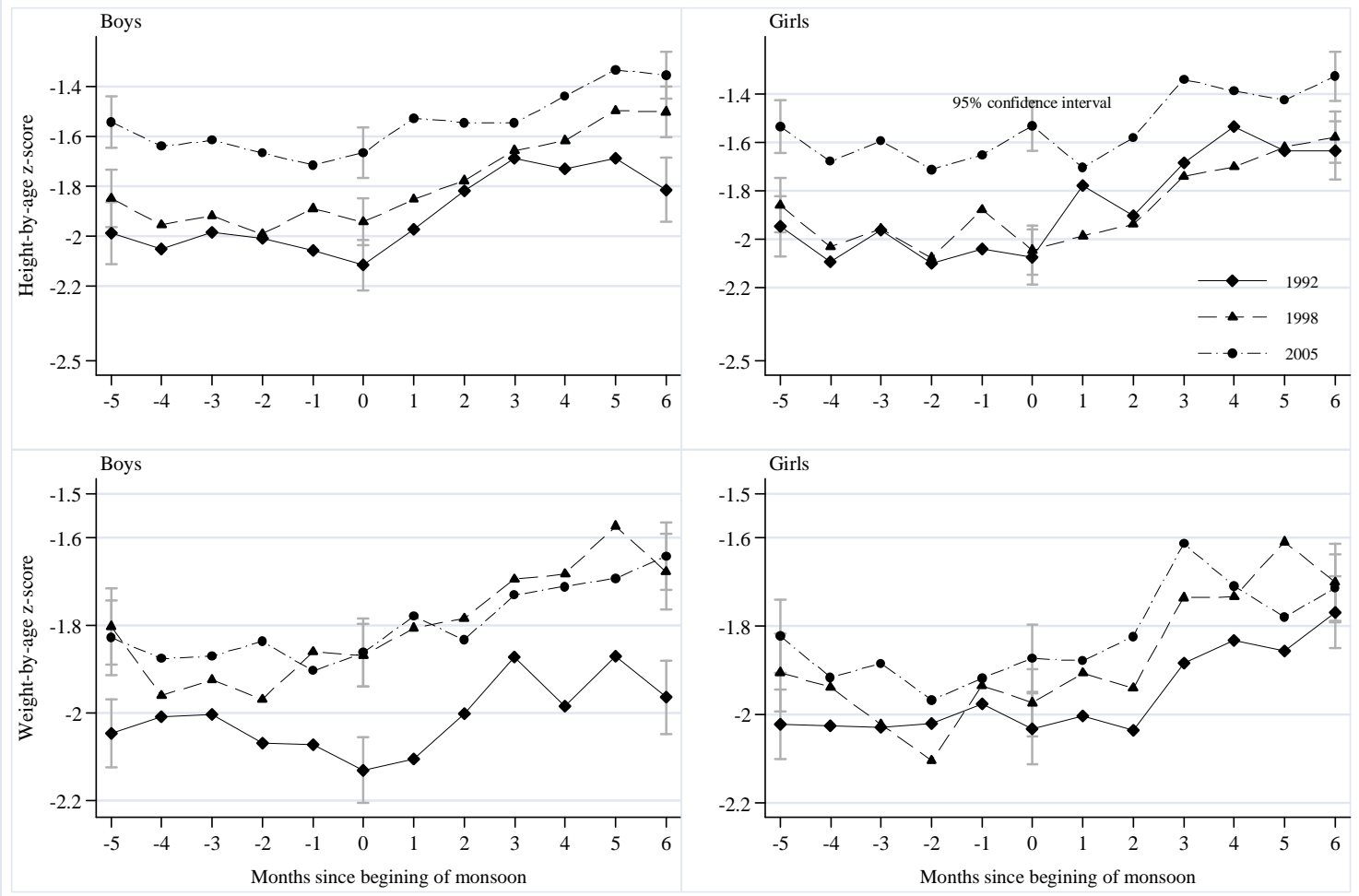

Figure 5: Health outcomes (WAZ and HAZ) by month of birth since the beginning of monsoon season and gender. India NFHS 1992, 1998 and 2005 